\title{
Established Numerical Techniques for the Structural Analysis of a Regional Aircraft Landing Gear
}

\author{
F. Caputo $\mathbb{D}^{1},{ }^{1}$ A. De Luca $\left(D,{ }^{1}\right.$ A. Greco, ${ }^{1}$ A. Marro, $^{2}$ A. Apicella, ${ }^{2}$ R. Sepe $\mathbb{D},{ }^{3}$ \\ and E. Armentani ${ }^{3}$ \\ ${ }^{1}$ Dept. of Engineering, University of Campania "L. Vanvitelli", Via Roma 29, 81031 Aversa, Italy \\ ${ }^{2}$ Magnaghi Aeronautica, Via Galileo Ferraris 76, 80142 Naples, Italy \\ ${ }^{3}$ Dept. of Chemical, Materials and Production Engineering, University of Naples Federico II, P.le V. Tecchio 80, \\ 80125 Naples, Italy
}

Correspondence should be addressed to R. Sepe; raffsepe@unina.it

Received 22 May 2018; Accepted 4 September 2018; Published 17 October 2018

Academic Editor: Pietro Russo

Copyright ( $\odot 2018$ F. Caputo et al. This is an open access article distributed under the Creative Commons Attribution License, which permits unrestricted use, distribution, and reproduction in any medium, provided the original work is properly cited.

Usually during the design of landing gear, simplified Finite Element (FE) models, based on one-dimensional finite elements (stick model), are used to investigate the in-service reaction forces involving each subcomponent. After that, the design of such subcomponent is carried out through detailed Global/Local FE analyses where, once at time, each component, modelled with threedimensional finite elements, is assembled into a one-dimensional finite elements based FE model, representing the whole landing gear under the investigated loading conditions. Moreover, the landing gears are usually investigated also under a kinematic point of view, through the multibody (MB) methods, which allow achieving the reaction forces involving each subcomponent in a very short time. However, simplified stick (FE) and MB models introduce several approximations, providing results far from the real behaviour of the landing gear. Therefore, the first goal of this paper consists of assessing the effectiveness of such approaches against a 3D full-FE model. Three numerical models of the main landing gear of a regional airliner have been developed, according to MB, "stick," and 3D full-FE methods, respectively. The former has been developed by means of ADAMS ${ }^{\circledR}$ software, the other two by means of NASTRAN ${ }^{\circledR}$ software. Once this assessment phase has been carried out, also the Global/Local technique has verified with regard to the results achieved by the 3D full-FE model. Finally, the dynamic behaviour of the landing gear has been investigated both numerically and experimentally. In particular, Magnaghi Aeronautica S.p.A. Company performed the experimental test, consisting of a drop test according to EASA CS 25 regulations. Concerning the 3D full-FE investigation, the analysis has been simulated by means of Ls-Dyna ${ }^{\circledR}$ software. A good level of accuracy has been achieved by all the developed numerical methods.

\section{Introduction}

The landing gear is one of the main and a complex engineering system of an aircraft and its weight may reach up to the $3 \%$ of the maximum aircraft weight at the take-off. Hence, the design phase of the landing gear has a heavy impact on the whole structure and on the airplane aerodynamic behaviour.

Specifically, its main scope is to support the aircraft during the landing, the tacking off, and ground operations, so it is mainly subjected during its lifecycle to heavy compressive loads, but also drag and side loads play a significant role [1]. Among the several loading conditions, the landing phase is the most severe and defines the main design specifications [1].

In fact, the landing gear's principal role is to absorb the impact energy minimizing the loads which would be transferred to the airframes and to the other parts of the aircraft, passengers included. The landing gear is composed by several components whose main scope is also addressed to the energy absorption; among these, the shock absorber plays a key-role. The energy absorption is an important design criterion which is also significantly considered in the passenger's passive safety criteria [1]. During the design current practice, some aircraft operations, which must be taken into account to assure the aircraft safety, are difficult to 
consider and are often postponed at later design stages by performing experimental tests on prototypes [2-4].

However, it may involve expensive design modifications in the case that the landing gear design fails to meet the customer and certification requirements. For these reasons, a prediction model able to simulate, with a good level of accuracy, the structural response of a landing gear under several landing conditions can be a helpful tool for designers.

Several works have been addressed to experimental and numerical investigations of landing gear performances as well as other aircraft structural components under the dynamic loads produced by a landing operation [5-13]. Furthermore, Daniels [14], proposed an approach for modelling and simulating landing gear systems. The model has been assessed against static and dynamic tests.

Niezgoda et al. [15] carried out numerical simulations for the investigation of the dynamic response of a landing gear. In his paper, he discussed the methods used for the static analysis and presented a mathematical model which allows determining the dynamic characteristics of the landing gear.

Infante et al. [16] presented a detailed analysis of a Nose Landing Gear (NLG) failure, supported by FE analyses. The investigation focused on an accident in which the nose of the landing gear fork of a light aircraft failed during landing. Imran et al. [1] focused on the structural components, made of composite materials, of a landing gear. Structural safety for static and spectrum loads is analysed by FEM (Finite Element Method).

Numerical methods are not only used for structural purposes. Actually, Redonnet et al. [17] proposed a numerical characterization of the aeroacoustics by a simplified nose landing gear, by using advanced simulation and signal processing techniques. To this end, the NLG noise physics is primarily simulated through an advanced hybrid approach, which relies on Computational Fluid Dynamics (CFD) and Computational AeroAcoustics (CAA) calculations.

Landing gear components are generally designed under a "safe life" approach, and its components are often replaced many times during the in-service life of the aircraft.

In fact, failures may lead to catastrophic consequences, with serious damages to the aircraft structure and, in the worst case scenario, possible loss of human lives. For this reason, the design phase requires a special attention. Damage investigation appears to be of vital importance in preventing accidents, so several authors are working on structural health monitoring systems for multiple and different applications. Concerning the damage types, fatigue cracking is the most common cause of structural failure in aircraft. Fujimoto and Gallagher [18] attributed to crack onset and propagation processing operations, latent material defects, mechanical damage, and crack growth from corrosion pits.

Viùdez-Moreiras et al. [19] investigated on the dynamic loads affecting main landing gear doors of an Airbus passenger aircraft. Currently, significant costs are invested by manufacturers in order to test the aerodynamic performance and the high costs associated to wind tunnel and flight testing restrict the number of test cases that can be performed. So, Viùdez-
Moreiras et al. [19] proposed a numerical model for the unsteady aerodynamics characterized by wind tunnel testing, in order to predict the aerodynamic effect in previously untested conditions and, in this way, to allow a first-stage exploration of new areas in the design space, without the need of expensive wind tunnel or flight testing.

In this scenario, the regulations $[20,21]$ precisely define the minimum requirements to be met during the design.

Concerning the landing gear current design practice, a preliminary stage is dedicated to the calculation of the loads acting on each subcomponent during all prescribed aircraft operations by means of simplified FE models, composed by one-dimensional finite elements (stick models). After that, the design of each subcomponent is carried out through detailed Global/Local FE analyses, consisting in replacing, once at time, each component modelled in stick model with one-dimensional finite elements, with a three-dimensional representation based on three-dimensional finite elements.

Other modelling techniques can be used for the calculation of the reaction forces, such as the multibody (MB) one. The benefits in using such method, rather than others, consists also of the possibility to analyse in a very short time the kinematic behaviour of a structure and, then, the displacements of the landing gear subcomponents, before the landing gear production. Hence, it is possible to verify the coherence of the space taken up by each subcomponent, which should not interfere with the motion of another one, and to estimate the current mass values, the equivalent stiffness, and the damping coefficients of the landing gear components.

The aim of this paper is to verify the reliability of the stick and MB approaches against a 3D full-FE model, which is the most reliable method but also the highest time-consuming one. Simplified stick and MB models can introduce too much approximations. It is well known that most of the approximations introduced by the stick model are related to the geometry, which is one-dimensionally modelled. Moreover, according to such approach, it is important, from a numerical point of view, to develop an isostatic FE model equivalent to the real one: if the landing gear is modelled as overconstrained, the static equilibrium equations are insufficient for determining the internal forces and reactions on each subcomponent. So, the modelled material properties and geometries assume an increasing importance, which gets the stick model a too approximated solution.

Concerning the MB approach, since each subcomponent is modelled as rigid and linked to the other subcomponents by means of ideal constraints, it is often necessary a proof tuning phase of the model.

In this paper, three numerical models have been developed, according to the stick, $\mathrm{MB}$, and $3 \mathrm{D}$ full-FE approaches, respectively. The models concern the main landing gear of a regional airliner.

Once this assessment phase has been carried out, the structural behaviours of the main fitting and the trailing arm landing gear components have been investigated according to the aforementioned Global/Local technique, by replacing alternatively their one-dimensional representation with the 3D one. The Global/Local technique has subsequently been 
assessed against the results obtained by a 3D full-FE model. A good agreement has been achieved in terms of stress-strain field.

Finally, the dynamic behaviour of the landing gear has been investigated both numerically and experimentally. In particular, Magnaghi Aeronautica S.p.A. Company performed the experimental test, consisting of a drop test carried out according to EASA CS 25 regulations [20]. Concerning the numerical investigation, the analysis has been simulated by means of Ls-Dyna ${ }^{\circledR}$ code, by developing a 3D full-FE model; a good level of accuracy has been achieved.

\section{Experimental Test Description}

The main landing gear of a regional airliner has been investigated (Figure 1).

Table 1 shows the material properties of the landing gear components.

The drop test has been conducted at Magnaghi Aeronautica Lab test (Figure 2).

\section{Numerical Techniques for Quasistatic Structural Analyses}

In this section, the three numerical models, based on the stick, $\mathrm{MB}$, and 3D full-FE approaches, are presented. All results are, respectively, compared to assess their accuracy. In addition, the Global/Local technique has been used to perform a structural analysis of the main landing gear subcomponents, and the results have been compared with the results achieved by a 3D full-FE model. All static FE analyses have been carried out by means of NASTRAN ${ }^{\circledR}$ code [22], whilst the MB analyses by means of $\mathrm{ADAMS}^{\circledR}$ code [23].

3.1. Stick Model. The stick model is often used to preliminarily explore the loads distribution on each subcomponent under particular loading condition and geometry configurations. This modelling strategy consists of modelling the whole structure by means of one-dimensional finite elements. According to the first modelling stage, the entire landing gear system has been modelled as shown in Figure 3. The developed FE model consists of 40 nodes and 42 finite elements (36 CBAR with 6 degrees of freedom for each node, 2 CROD with 1 degree of freedom for each node and 4 RBE2), and it is characterized by the boundary conditions shown in Figure 3.

This phase is often followed by a Global/Local analysis in which the subcomponents of greatest interest, previously modelled with one-dimensional finite elements, are alternately modelled by means of three-dimensional finite elements and replaced to the ones one-dimensionally modelled (Figure 4). In this way, it is possible to take advantage by the 3D modelling only where needed and to perform structural analysis only on the subcomponent of greatest interest, considerably reducing the computational time required by a $3 \mathrm{D}$ full-FE model.

As a result of such analysis, the landing gear will be characterized by two parts (Figure 4): (i) Global part: some components coarsely modelled with one-dimensional finite elements, which play only the role of loads transfer;

(ii) Local part: a component (either the trailing arm or the main fitting) finely modelled with 3D finite elements, on which the stress analysis can be performed. Actually, the internal loads generated also by the interaction of all the other components modelled with one-dimensional finite elements will act on each $3 \mathrm{D}$ component.

3.2. Multibody Model. Even if, in this paper, the multibody approach has been used to predict the reaction forces for the landing gear under static loading conditions, the MB approach allows investigating both the kinematic and the dynamic behaviours of a structure. In general, the main use of such methodology must be found in the possibility to understand trajectory and kinematic of the landing gear subcomponents, before the landing gear production.

The components have been modelled as rigid and linked reciprocally by means of ideal constraints, neglecting both elasticity and related friction. The inertia properties are automatically considered in the developed model by introducing the density in the material properties. The MB model (Figure 5(a)) has been developed in order to reproduce the landing gear schematically as shown in Figure 5(b).

Different joint types have been introduced in the model: revolute joints, allowing the motion between the trailing arm, the main fitting, and the shock absorber (Figure 6(a)); revolute joints modelled between the folding side brace, the main fitting, and the support fixture (Figure 6(b)); and prismatic joints, allowing the sliding between the piston and the cylinder tube of the shock absorber.

3.3. Full-FE Model. In order to assess the reliability of the stick and $\mathrm{MB}$ modelling techniques, a full-FE model, characterized by three-dimensional finite elements, has been developed. The full-FE model consists of 1500328 elements and 351676 nodes, whose 1500297 are CTETRA4 elements (four nodes with three freedom degrees for each node), whilst the remaining part (31) are RBE2 elements. The construction of the full-FE model is similar to the one used for the dynamic analysis, so, for the sake of brevity, a more detailed description of the 3D full-FE model is postponed in Section 5. As a result, this subsection is mainly dedicated to the description of the modelled boundary conditions (Figure 7). More in detail, rigid elements RBE2 have been used to model the joints. The analysis has been carried out by means of NASTRAN ${ }^{\circledR}$ code.

Since the attention is paid on the calculation of the reaction forces, it must be noticed that, in this model, contrary to the one addressed to the dynamic analysis, tyres have not been modelled (Figure 7).

\section{Results Analysis}

All three modelling techniques have been investigated under the same loading conditions, characterized by two vertical 


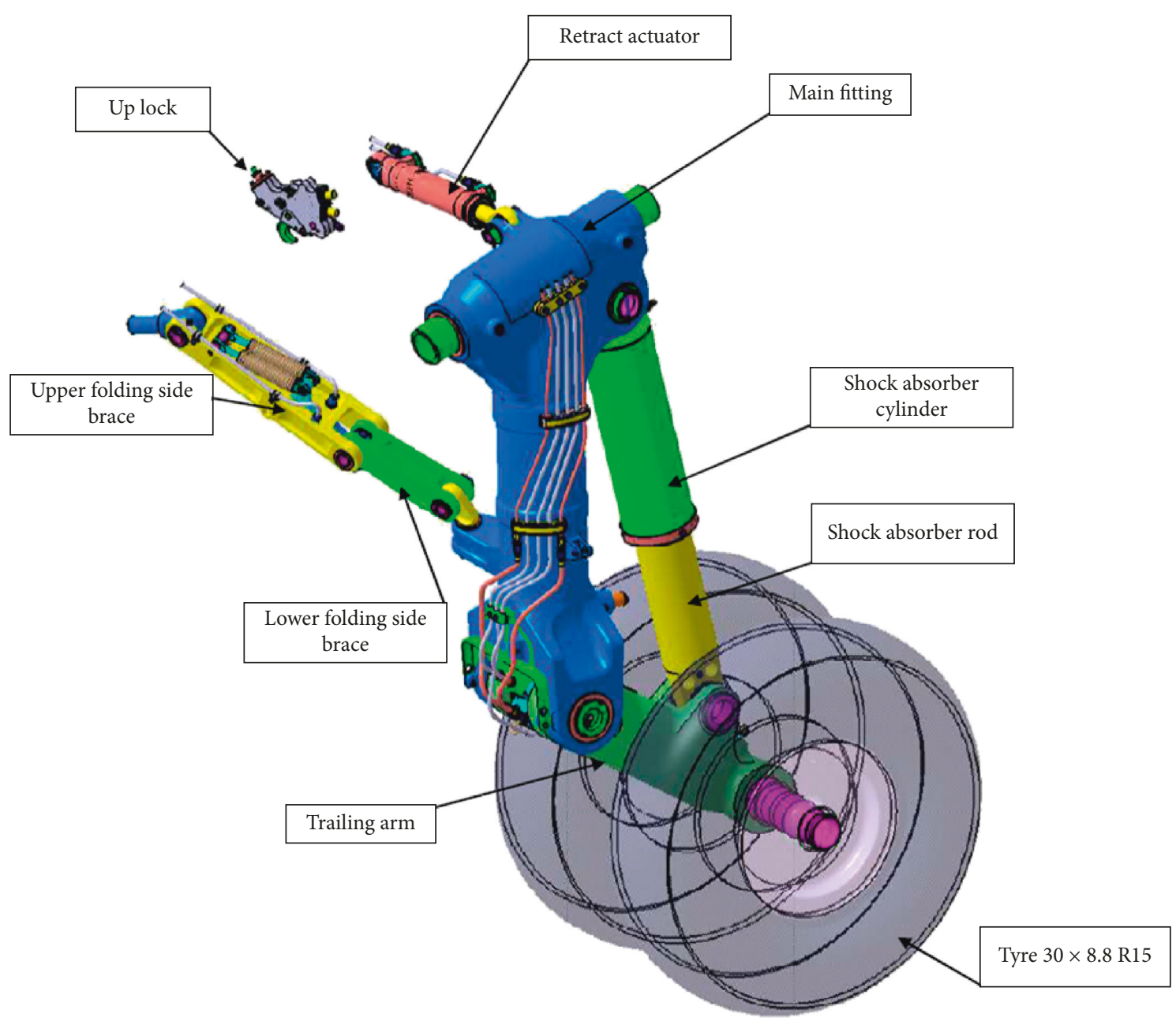

Figure 1: Main landing gear.

TABLE 1: Material properties.

\begin{tabular}{lc}
\hline Material properties & \\
\hline Wheel axle & 300M AMS6257 \\
Main fitting/trailing arm & AL7175-T74 AMS 4149 \\
Folding side brace & Ti6Al4V AMS4928 \\
Shock absorber cylinder & 4340 AMS 6414 \\
\hline
\end{tabular}

forces of $78800 \mathrm{~N}$ applied to the wheels, by assuming a shock absorber stroke of $75 \%$ of the total mechanical stroke.

The results, in terms of reaction forces, achieved by the three numerical modelling techniques have been presented and compared in Table 2.

According to Table 2, a significant disagreement can be noticed between the reaction forces. Such disagreement has been addressed to the 3D FE model and, in particular, to the joint modelling between the lower folding side brace and the main fitting, which consists of rigid elements. In fact, by replacing the whole folding side brace with a beam element (Figure 8), a very better agreement can be observed (Table 3 ).

According to Table 3, a very high level of accuracy among the three numerical modelling techniques can be observed.
As a result of the very good agreement, the structural behaviours of the main fitting and the trailing arm components have been investigated according to the aforementioned Global/Local technique, by replacing alternatively their one-dimensional representation with the $3 \mathrm{D}$ one. In addition, in order to assess the reliability of this technique, the numerical results, in terms of von Mises stresses map, have been compared with the 3D full-FE model ones. The von Mises stresses maps achieved by both Global/Local and full-FE techniques have been, respectively, compared in Figures 9(a) and 9(b), for the trailing arm and in Figures 10(a) and 10(b) for the main fitting.

According to Figures 9 and 10, the contour plots of the von Mises stresses for the trailing arm and for the main fitting are quantitatively and qualitatively in good agreement.

Moreover, the stick model has also been used to investgate the reaction forces at the constraints under dynamic loading conditions, such as during the landing phase. In particular, such condition has been investigated according to the FAA Part 23, assuming that the landing occurs with only the main wheels contacting the ground in the "tail down" landing configuration. Two vertical forces of 104256 N, provided by Magnaghi Aeronautica S.p.A., 


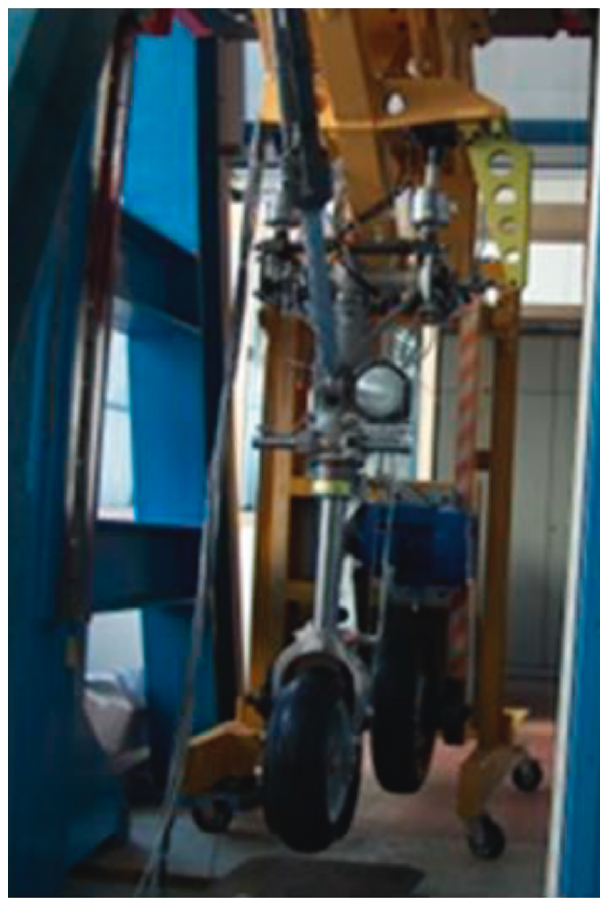

FIGURE 2: Laboratory for experimental drop test.

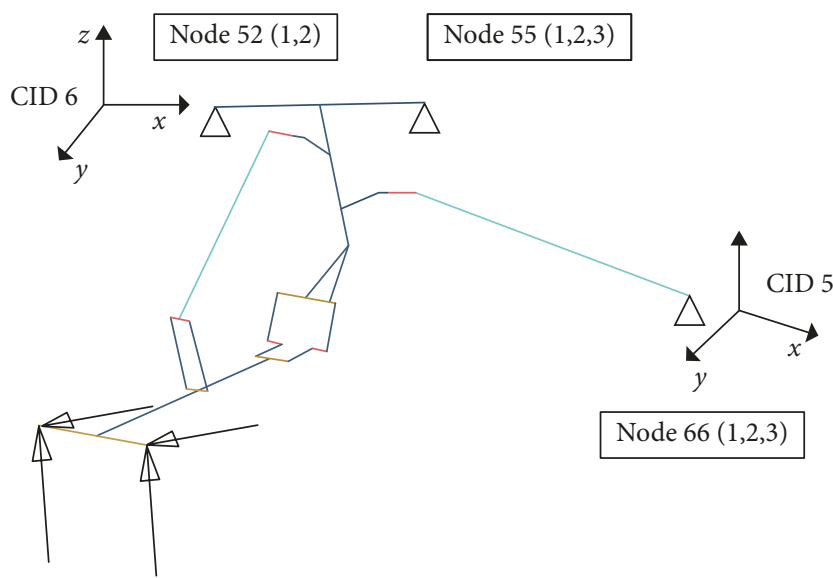

FIGURE 3: Stick model of the landing gear.
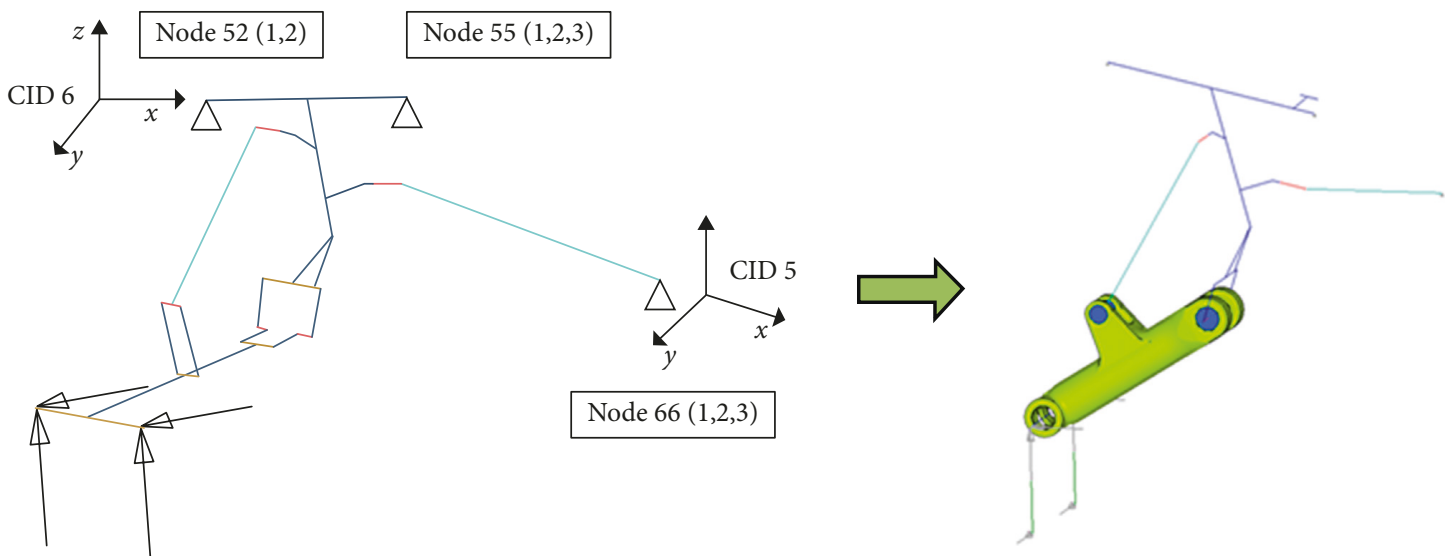

Figure 4: Global/local technique. 


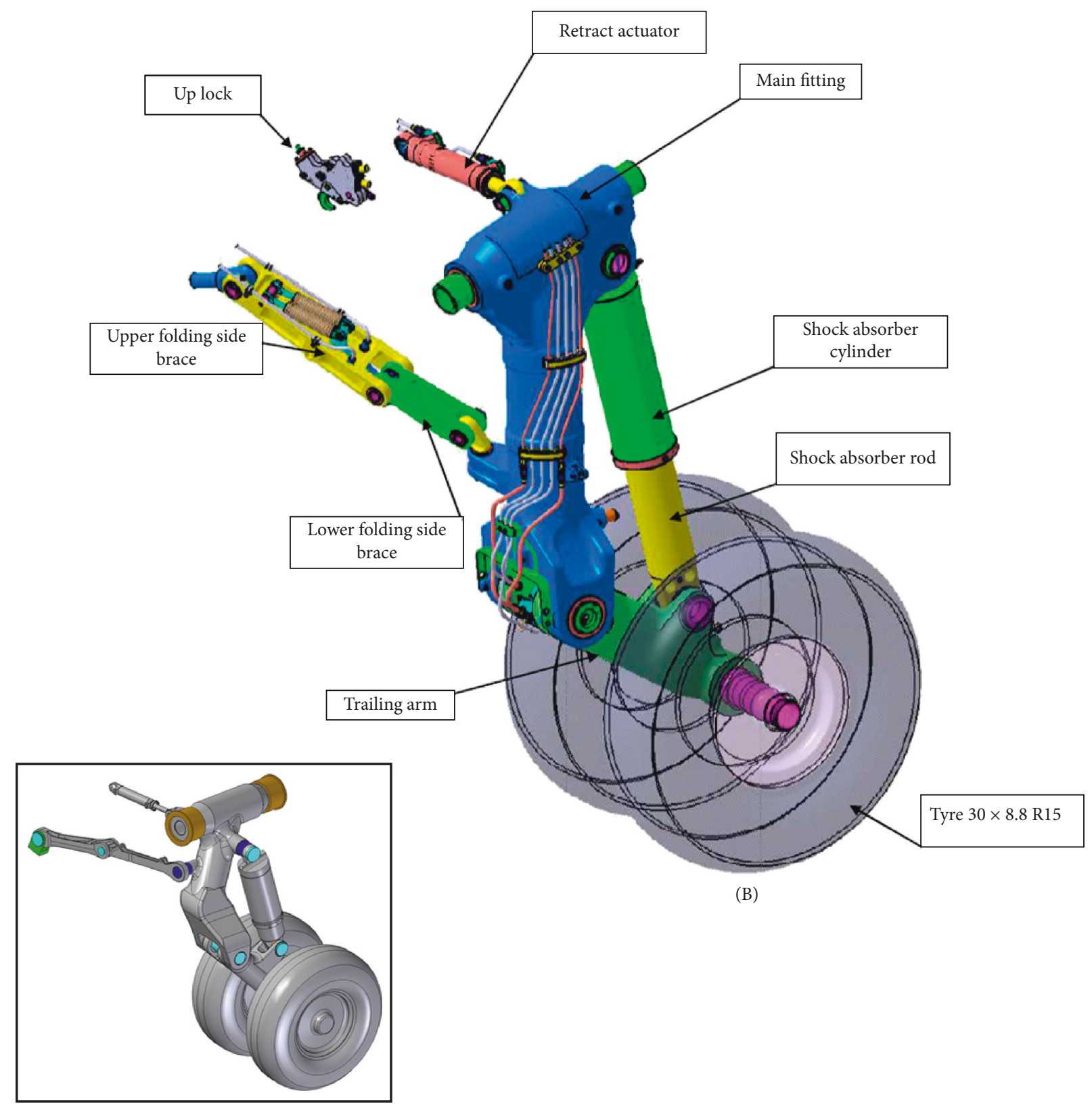

(A)

FiguRE 5: Landing gear: (A) multibody model; (B) main structural components.

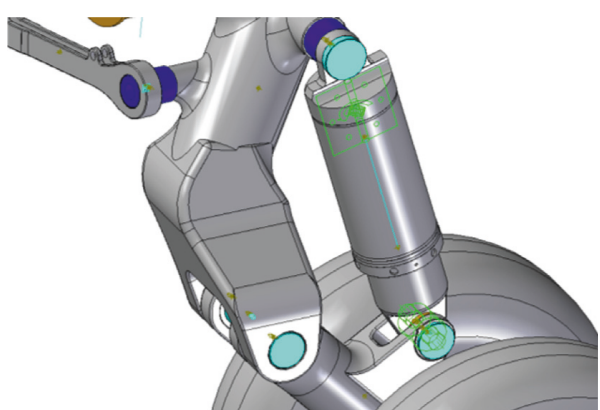

(a)

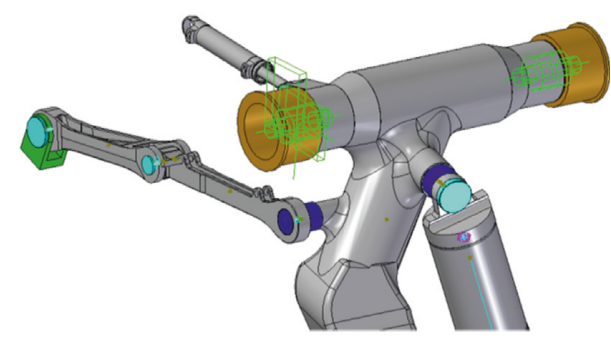

(b)

FiguRE 6: Revolute joints between: (a) main fitting, trailing arm, and shock absorber; (b) main fitting and support fixture. 


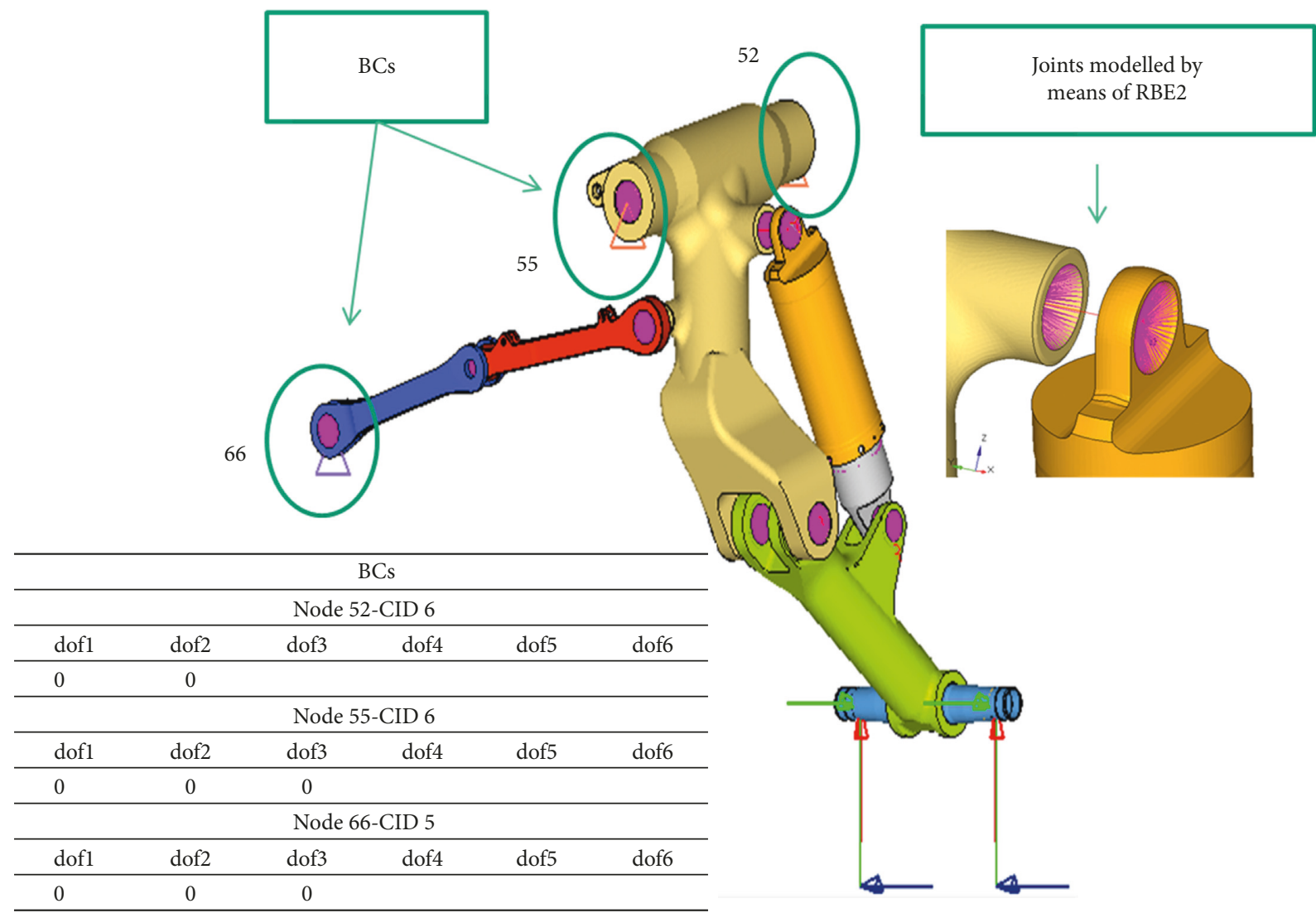

Figure 7: Boundary conditions (BCs) acting on the 3D full-FE model.

TABLE 2: Reaction forces achieved for the main landing gear by the stick, 3D FE, and MB models.

\begin{tabular}{lccc}
\hline & Rx $(\mathrm{N})$ & $\mathrm{Ry}(\mathrm{N})$ & $\mathrm{Rz}(\mathrm{N})$ \\
\hline Node 52 & & & \\
Stick & 25290 & 3463 & -160000 \\
3D FEM & 25360 & 2113 & -158800 \\
MB & 25293 & 3453 & -160003 \\
Differences & $(\%)$ & $(\%)$ & $(\%)$ \\
Stick-3D FE & -0.28 & 63.89 & 0.76 \\
MB-3D FE & -0.26 & 63.42 & 0.76 \\
Stick-MB & -0.01 & 0.29 & 0.00 \\
\hline Node 55 & & & \\
Stick & 17390 & -262000 & 54490 \\
3D FEM & 21400 & -265400 & 49120 \\
MB & 17395 & -261989 & 54479 \\
Differences & $(\%)$ & $(\%)$ & $(\%)$ \\
Stick-3D FE & -18.74 & -1.28 & 10.93 \\
MB-3D FE & -18.71 & -1.29 & 10.91 \\
Stick-MB & -0.03 & 0.00 & 0.02 \\
\hline Node 66 & & & \\
Stick & -42690 & 258500 & -52080 \\
3D FEM & -46750 & 263300 & -47960 \\
MB & -42688 & 258536 & -52077 \\
Differences & $(\%)$ & $(\%)$ & $(\%)$ \\
Stick-3D FE & -8.68 & -1.82 & 8.59 \\
MB-3D FE & -8.69 & -1.81 & 8.58 \\
Stick-MB & 0.00 & -0.01 & 0.01 \\
\hline
\end{tabular}

representative of the "tail down" configuration, have been applied to the wheel centres of the stick model.

The reaction forces for both static and dynamic loading conditions are shown in Table 4.

\section{Full-FE Dynamic Analysis}

Numerical full-FE model has been developed for simulating dynamic loading conditions, such as the landing phase. More in detail, according to this technique, all landing gear subcomponents have been modelled with three-dimensional finite elements and the simulation has been carried out by means of Ls-Dyna ${ }^{\circledR}$ [24] solver. A nonlinear analysis in terms of both material and geometry has been carried out. The model, shown in Figure 11, counts a total of 448833 nodes and 1222238 of three-dimensional finite elements. The elements used in the model are reported in Table 5. Moreover, rigid elements RBE2, discrete elements, and revolution joints elements have been used in order to model the joints between the components.

Because of the complexity of the analysis, the modelling of landing gear has been carried out step-by-step.

A particular attention has been paid on the modelling of the shock absorber and the tyre, which need a tuning phase to replicate as better as possible their real structural responses. The description of the developed modelling tech- 


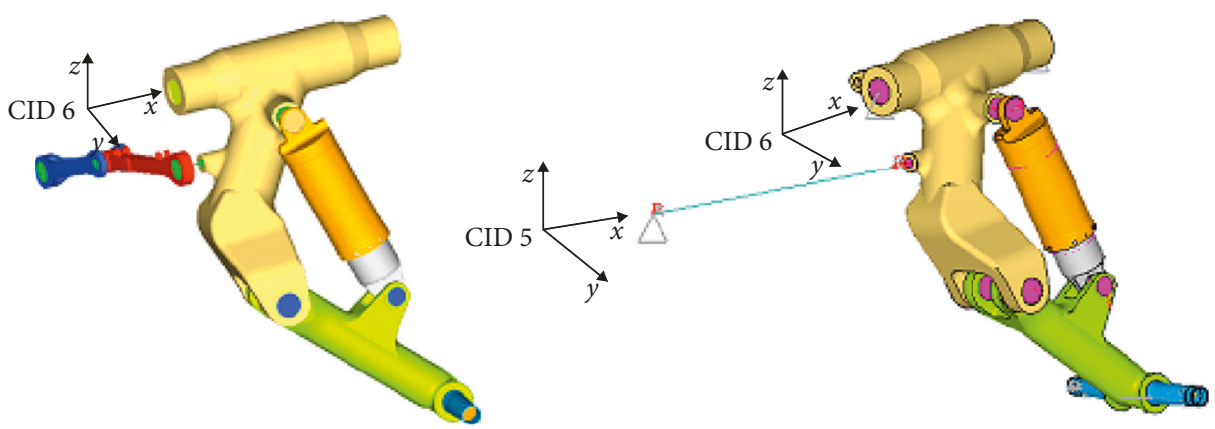

Figure 8: 3D full-FE model: second strategy.

TABLE 3: Reaction forces achieved for the main landing gear by the stick, modified 3D FE $\left({ }^{*}\right)$, and $\mathrm{MB}$ models.

\begin{tabular}{lccc}
\hline & $\mathrm{Rx}$ & $\mathrm{Ry}$ & $\mathrm{Rz}$ \\
\hline Node 52 & & & \\
& $(\mathrm{N})$ & $(\mathrm{N})$ & $(\mathrm{N})$ \\
Stick & 25290 & 3463 & -160000 \\
3D FEM* & 25290 & 3462 & -160000 \\
MB & 25293 & 3453 & -160003 \\
Differences & $(\%)$ & $(\%)$ & $(\%)$ \\
Stick-3D FE & 0.00 & 0.03 & 0.00 \\
MB-3D FE & 0.01 & -0.26 & 0.00 \\
Stick-MB & -0.01 & 0.29 & 0.00 \\
\hline Node 55 & & & \\
& $(\mathrm{N})$ & $(\mathrm{N})$ & $(\mathrm{N})$ \\
Stick & 17390 & -262000 & 54490 \\
3D FEM* & 17400 & -262000 & 54480 \\
MB & 17395 & -261989 & 54479 \\
Differences & $(\%)$ & $(\%)$ & $(\%)$ \\
Stick-3D FE & -0.06 & 0.00 & 0.02 \\
MB-3D FE & -0.03 & 0.00 & 0.00 \\
Stick-MB & -0.03 & 0.00 & 0.02 \\
\hline Node 66 & & & \\
& $(\mathrm{N})$ & $(\mathrm{N})$ & $(\mathrm{N})$ \\
Stick & -42690 & 258500 & -52080 \\
3D FEM* & -42690 & 258500 & -52070 \\
MB & -42688 & 258536 & -52077 \\
Differences & $(\%)$ & $(\%)$ & $(\%)$ \\
Stick-3D FE & 0.00 & 0.00 & 0.02 \\
MB-3D FE & 0.00 & 0.01 & 0.01 \\
Stick-MB & 0.00 & -0.01 & 0.01 \\
\hline & & &
\end{tabular}

niques of these two components is demanded in Sections 5.1 and 5.2, respectively.

Concerning the interactions among all components, the joints among the subcomponents have been simulated by means of one-dimensional rigid-finite elements stars and can be mainly grouped in two categories: spherical and cylindrical joints.

For example, Figure 12(a) shows the spherical joint modelled between the main fitting and the shock absorber; Figure 12(b) shows the cylindrical joint modelled between the trailing arm and the shock absorber.

In order to ensure the motion between the main fitting and the trailing arm, a cylindrical pin has been modelled as shown in Figure 13.

Another constraint type, shown in Figure 14, has been defined in order to ensure the motion between the wheels and the axle.
Moreover, differently from the stick model, also the secondary actuation system has been modelled (Figure 15) by introducing elastic and viscous finite elements, characterized by a constant elastic stiffness of $50 \mathrm{kN} / \mathrm{mm}$ and a damping factor of $50 \mathrm{kN} \cdot \mathrm{ms} / \mathrm{mm}$.

The ground has been modelled by means of a rigid wall; a "contact-automatic-surface-to-surface" algorithm has been defined to avoid the penetration between the rigid wall and the tyres.

In order to simplify the simulation, the drop velocity is attributed to the rigid wall along the $z$-axis (Figure 16(a)), keeping fixed the whole landing gear shown in both side (Figure 16(a)) and top (Figure 16(b)) views in Figure 16.

The FE analysis has been set for reproducing the specifications described by the EASA CS25 regulations, under which the experimental test has been carried out. Such regulations define all the test requirements, including the calculation of the equivalent airplane mass resting on the landing gear to be implemented during the test. The modelled mass assumes a value of $10800 \mathrm{~kg}$, and it has been numerically applied to the rigid wall.

A drop velocity of $3.05 \mathrm{~m} / \mathrm{s}$ has been applied to the rigid wall. Moreover, a rotational speed of $44.64 \mathrm{~m} / \mathrm{s}$ has been applied to the wheels, and a $0^{\circ}$ pitch angle has been considered. The dynamic simulation has been carried out by setting an analysis time of $450 \mathrm{~ms}$.

5.1. Shock Absorber Modelling. In order to model the shock absorber, a detailed modelling technique, enabling the sliding of the piston inside the cylinder tube, has been carried out by defining a contact surface between them. A "contact-automatic-surface-to-surface-offset" algorithm has been set by choosing the piston as master surface and the internal surface of the cylinder as slave (Figure 17). In particular, an offset between these two surfaces, which is kept constant during the sliding, has been imposed. It has been possible to keep the gap constant, by constraining the piston to slide axially inside the cylinder tube (Figure 17).

Moreover, it has been possible to model the damping and elastic responses by placing two overlapped onedimensional finite elements between the shock absorber ends: a beam element and discrete spring element (both represented by the yellow line in Figure 17). The two 


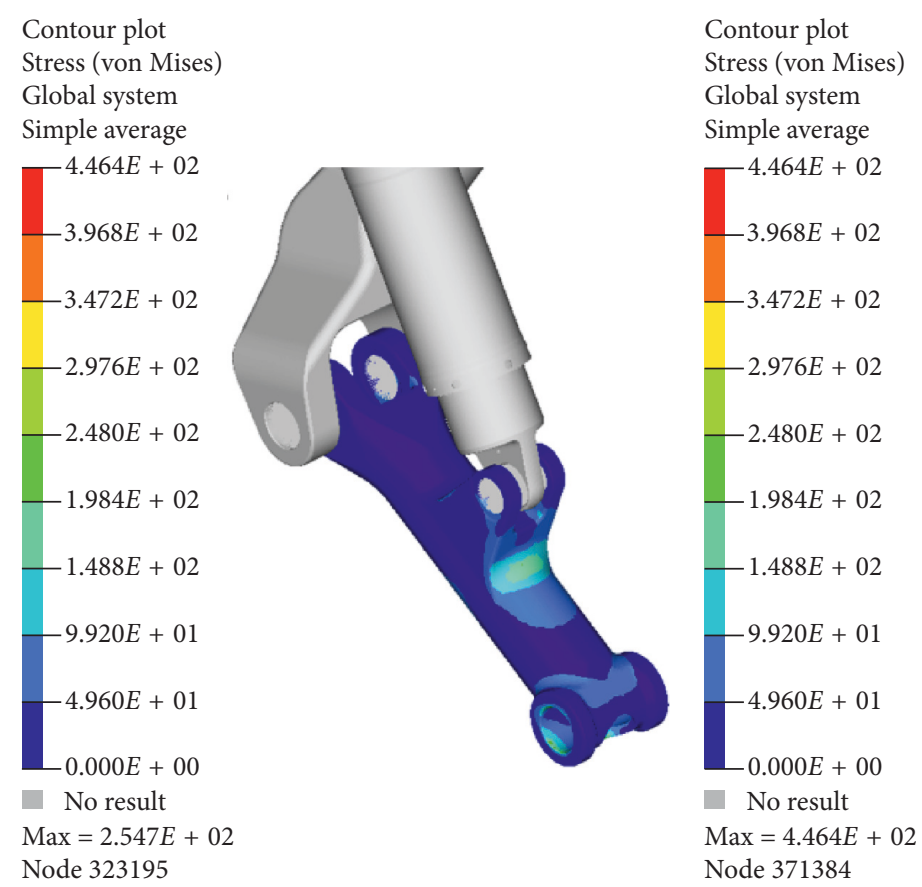

(a)

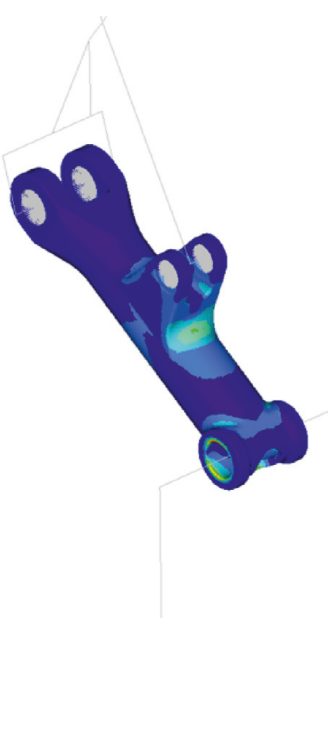

(b)

Figure 9: von Mises stresses (MPa) for the trailing arm achieved by (a) 3D full-FE model and (b) Global/local technique.

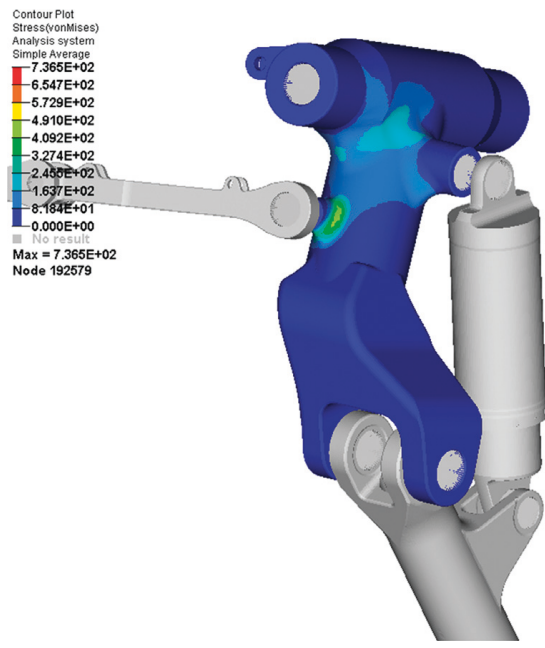

(a)

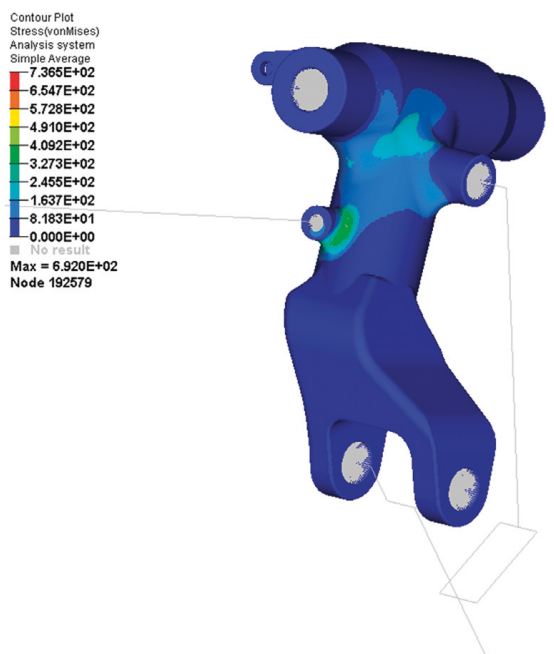

(b)

FIgURE 10: von Mises stresses (MPa) for the trailing arm achieved by (a) 3D full-FE model and (b) Global/local technique.

TABLE 4: Static and dynamic loading conditions (stick model).

\begin{tabular}{lccc}
\hline & $\mathrm{Rx}(\mathrm{N})$ & $\mathrm{Ry}(\mathrm{N})$ & $\mathrm{Rz}(\mathrm{N})$ \\
\hline Node 52 & & & \\
Stick static load & 25293 & 3453 & -160003 \\
Stick dynamic load & -14420 & -97770 & -35078 \\
\hline Node 55 & & & \\
Stick static load & 17395 & -261989 & 54479 \\
Stick dynamic load & 102047 & -154301 & -350578 \\
\hline Node 66 & & & \\
Stick static load & -42688 & 258536 & -52077 \\
Stick dynamic load & -87626 & 252071 & -177144 \\
\hline
\end{tabular}

one-dimensional finite elements share, thus, the same nodes. The discrete spring element allowed introducing the spring property (Figure 18), whilst the beam element the damping property (Figure 19) of the shock absorber.

It has been possible to assess the efficiency of this modelling technique by performing a simple simulation. In particular, the two coupled one-dimensional finite elements responses (Figure 20(a)) have been investigated under an imposed displacement curve (Figure 20(b)). The two finite elements share the same nodes and, in particular, the upper one is fully constrained, whilst the bottom is 


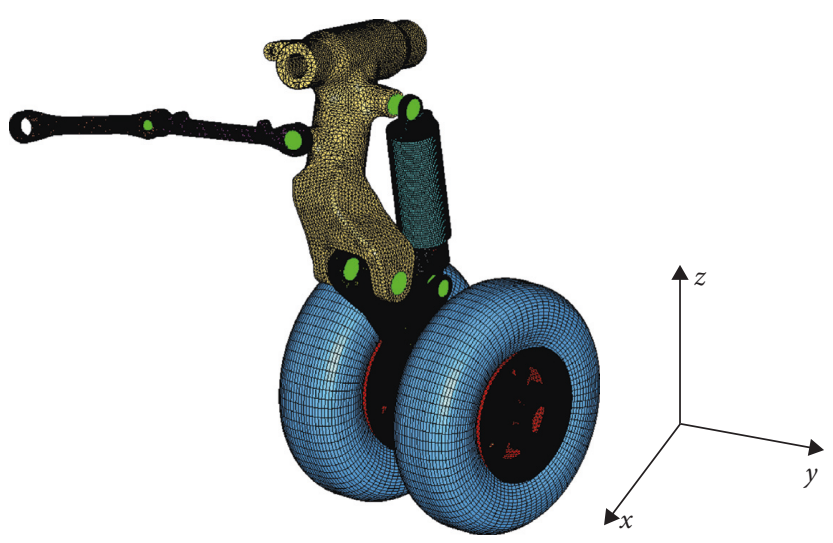

Figure 11: FE model.

TABle 5: Element types used in full-FE dynamic model.

\begin{tabular}{lcc}
\hline Element type & Number & Freedom degrees \\
\hline CTETRA4 (solid with four nodes) & 670428 & 3 for each node \\
HEX8 (solid with eight nodes) & 6100 & 3 for each node \\
SHELL4 (shell with four nodes) & 25838 & 6 for each node \\
SHELL3 (shell with three nodes) & 481764 & 6 for each node \\
PENTA6 (solid with six nodes) & 30080 & 3 for each node \\
\hline
\end{tabular}

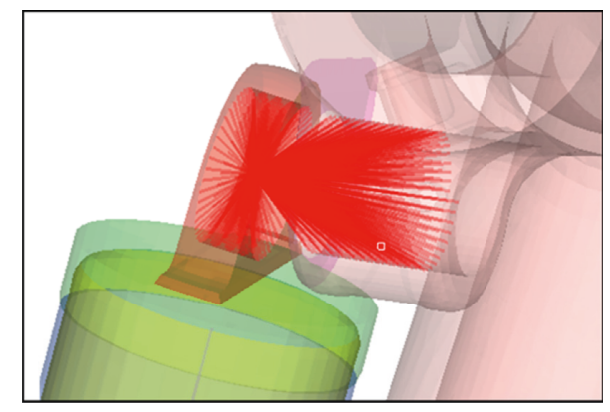

(a)

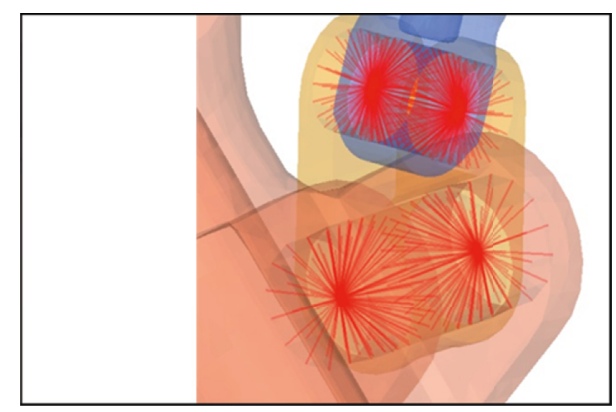

(b)

FIGURE 12: (a) Spherical and (b) cylindrical joints.

characterized by the displacement curve shown in Figure 20(b).

Figure 21 shows the results provided by FE analysis in terms of force vs. shock absorber stroke.

Hence, the maximum shock absorber stroke is of $150 \mathrm{~mm}$ (Figure 22).

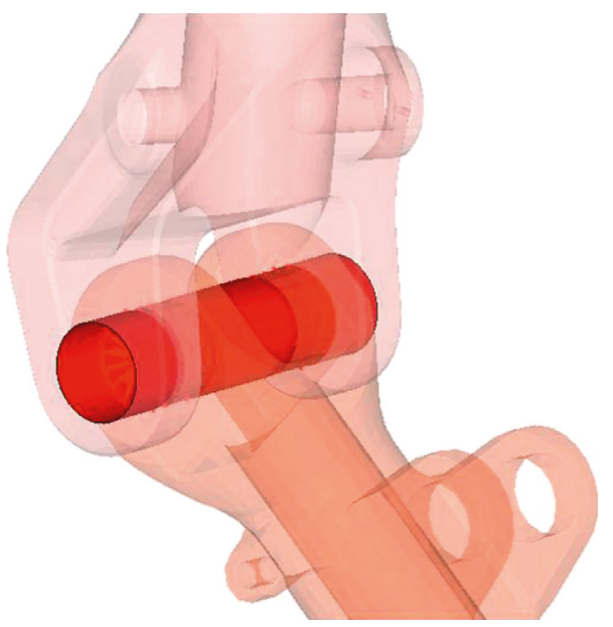

FIgURE 13: Pin linking the main fitting and the trailing arm.

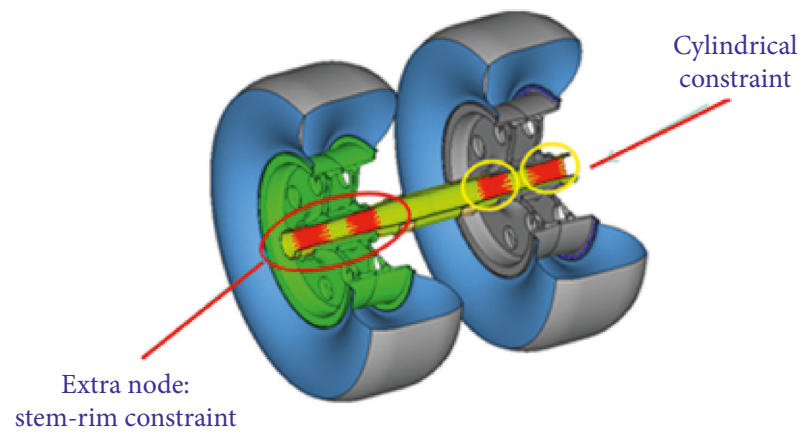

Figure 14: Modelling of the joints between wheels and axle.

5.2. Tyre Modelling. Concerning the modelling of the wheel $(\mathrm{H} 38 \times 13.0 \mathrm{R} 18)$, the tyre inflating has been modelled by using the same technique used in the aerospace field for modelling the airbag. It starts by the definition of a closed surface (tyre tube), containing a control volume (Figure 23), inflated by introducing a mass flow rate up to reach the desired pressure value ( 8.25 bar).

In addition, two sets of radial spring finite elements (Figure 24), each one characterized by a variable spring 


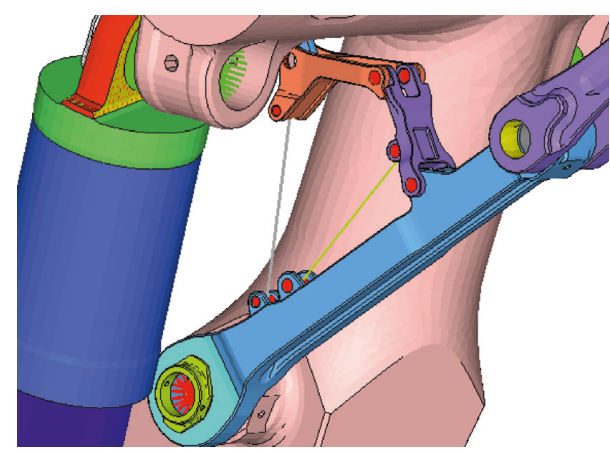

FIgURE 15: Secondary actuation system.

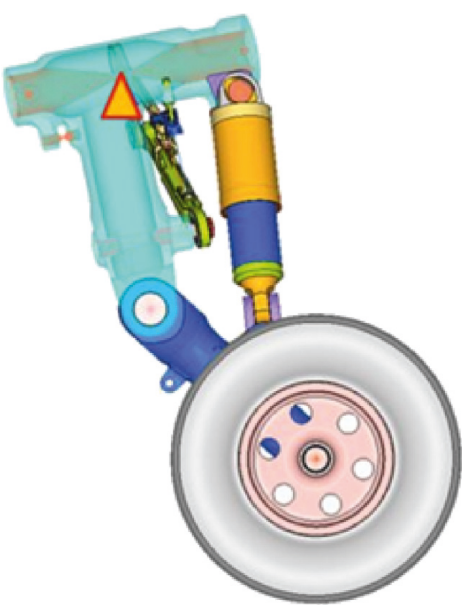

(a)

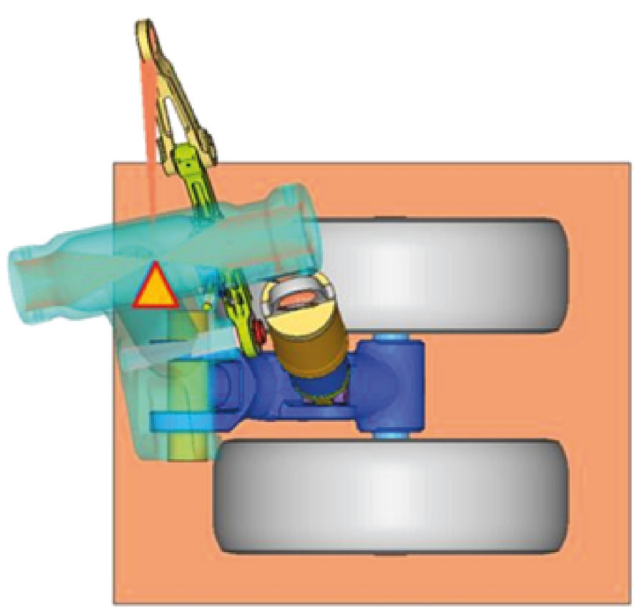

(b)

FIGURE 16: Landing gear model: (a) side and (b) top views.

stiffness carried out by the experimental data, shown in Figure 25, have been added.

This modelling technique allowed achieving a good level of accuracy between numerical and experimental force vs. tyre displacement curves, as shown in Figure 26.

The sensitivity of the model has been tested by varying the tyre pressure. Pressures of 4.76 bar and 11.85 bar have been considered. The force vs. deflection curves are shown in Figure 27.
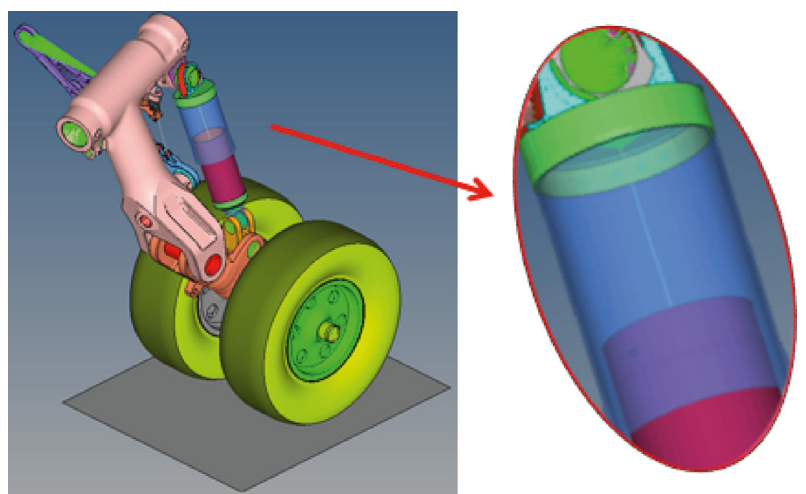

FIgURE 17: Modelling of the shock absorber.

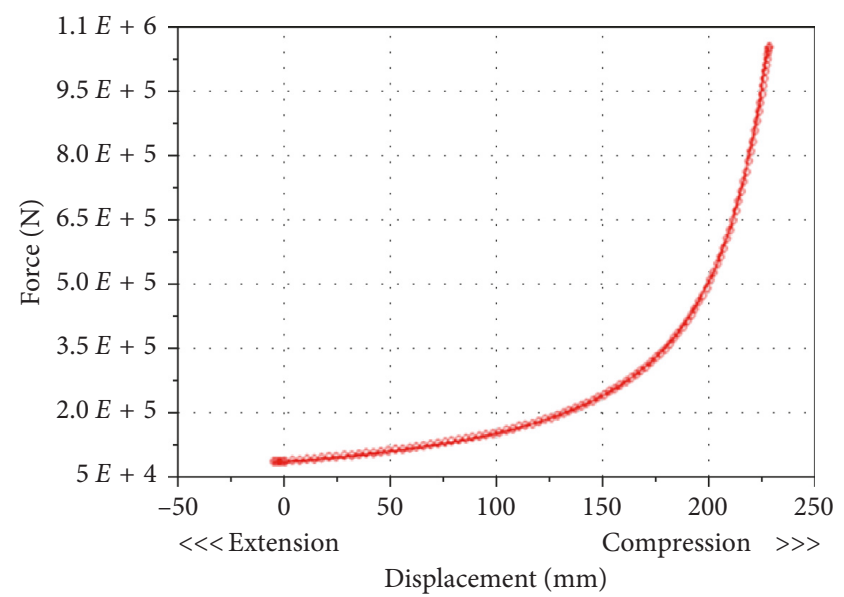

Figure 18: Polytrophic curve.

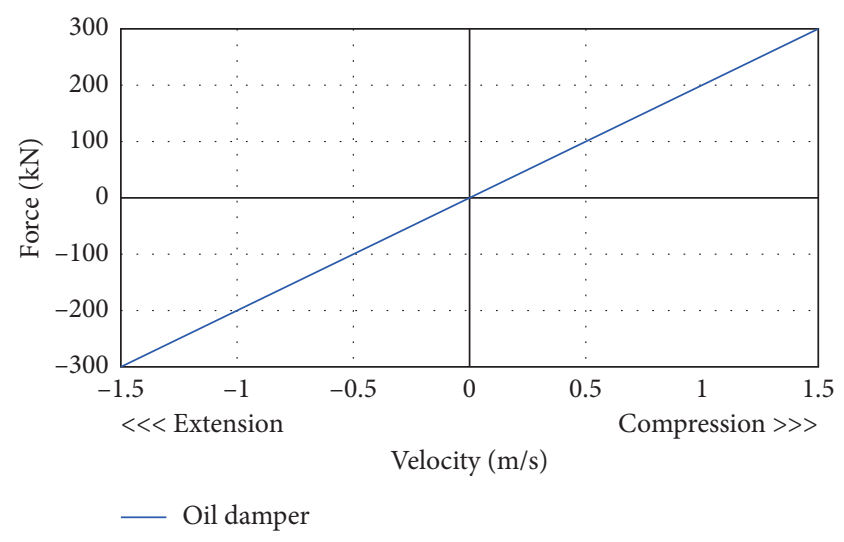

Figure 19: Oil damper properties.

\section{Full-FEM Assessment: Numerical- Experimental Correlation}

Figure 28 shows some numerical frames of the drop test simulation.

First of all, the assessment of the prediction capability of the performed simulations has been carried out, by 


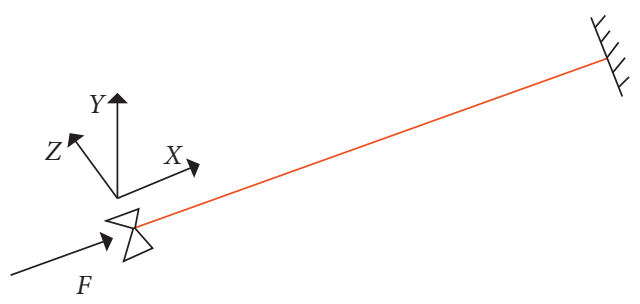

(a)

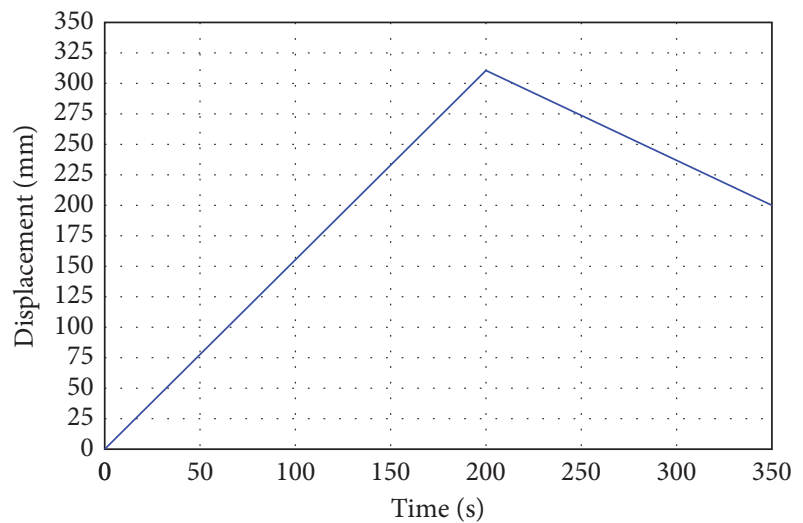

_ Nodal Point2-resultant displacement

(b)

Figure 20: (a) shock absorber model; (b) imposed displacement curve.

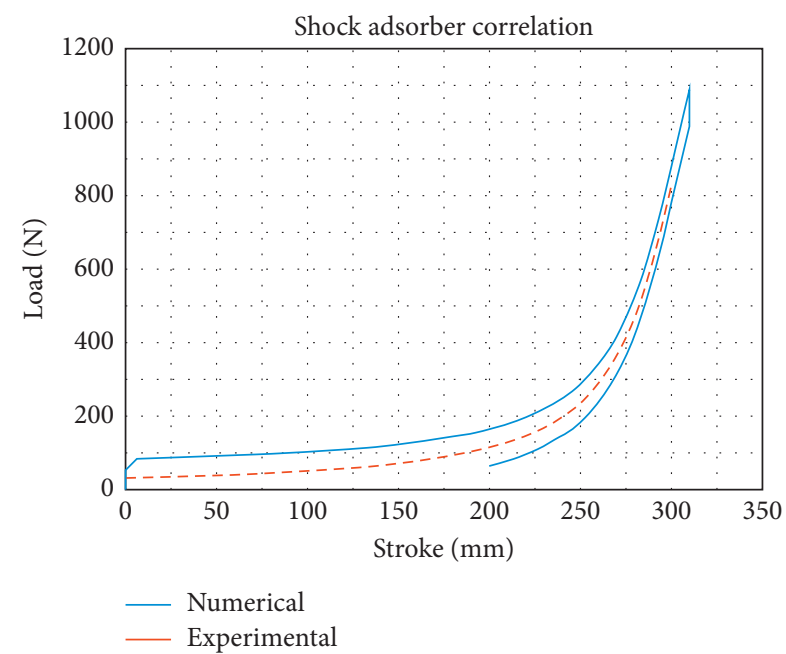

FIgURE 21: Force vs. shock absorber stroke curve.

comparing the numerical and experimental shock absorber stroke vs. rigid wall displacement curves (Figure 29(a)). The numerical results have been compared with the results carried out by two experimental tests, performed with pitch angles of $0^{\circ}$ and $5.94^{\circ}$, respectively.

According to Figure 29(a), the numerical curve fits properly the experimental one related to the $0^{\circ}$ pitch angle up to a wheel displacement of $250 \mathrm{~mm}$; after that, the numerical curve slope decreases and the curve fits better the experimental one related to a $5.95^{\circ}$ pitch angle. As a result, a good

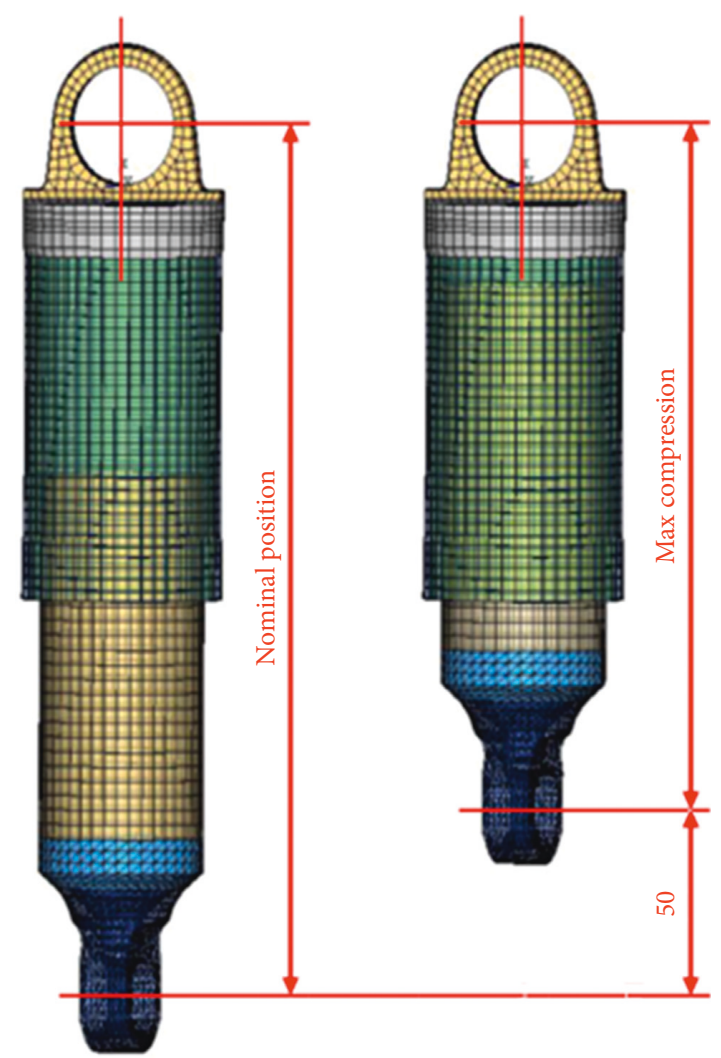

FIGURE 22: Shock absorber stroke.

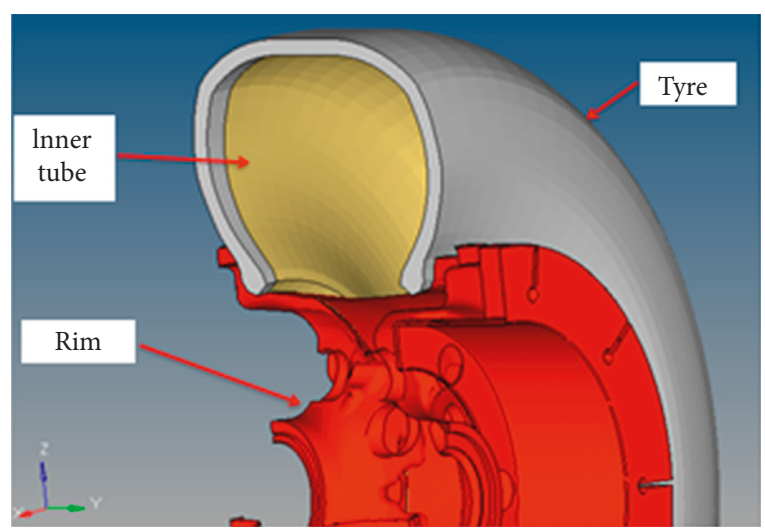

FIGURE 23: Modelling of the tyre.

agreement has been achieved. Figures 29(b) and 29(c) show the stroke and the rigid wall displacement vs. time curves, respectively.

According to Figure 29(a), the numerical curve fits properly the experimental one related to the $0^{\circ}$ pitch angle up to a wheel displacement of $250 \mathrm{~mm}$; after that, the numerical curve slope decreases, and the curve fits better the experimental one related to a $5.95^{\circ}$ pitch angle. As a result, a good agreement has been achieved. Figures 29(b) and 29(c) show the stroke and the rigid wall displacement vs. time curves, respectively. The numerical contact force between tyres and the rigid wall has been illustrated in Figure 30. 


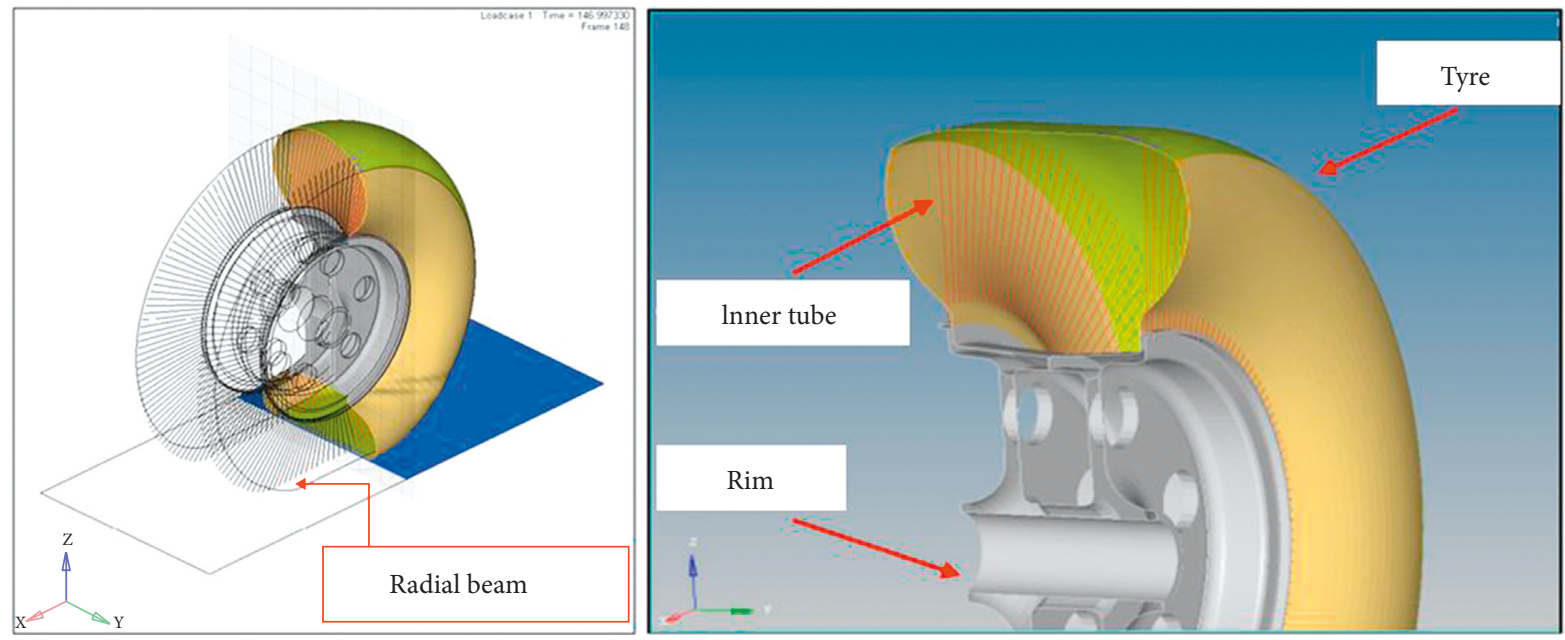

Figure 24: Tyre modelling.

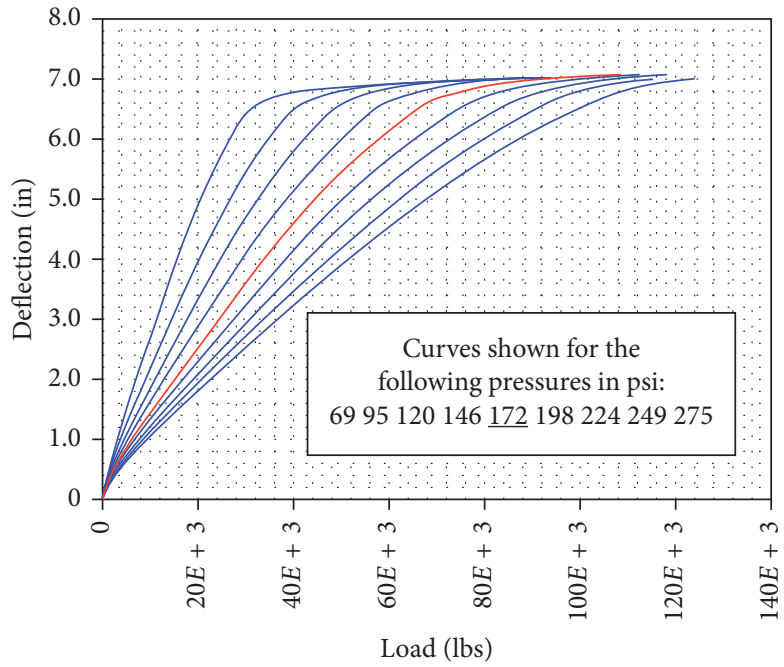

Figure 25: Experimental data of a H38 × 13.0 R18 tyre.

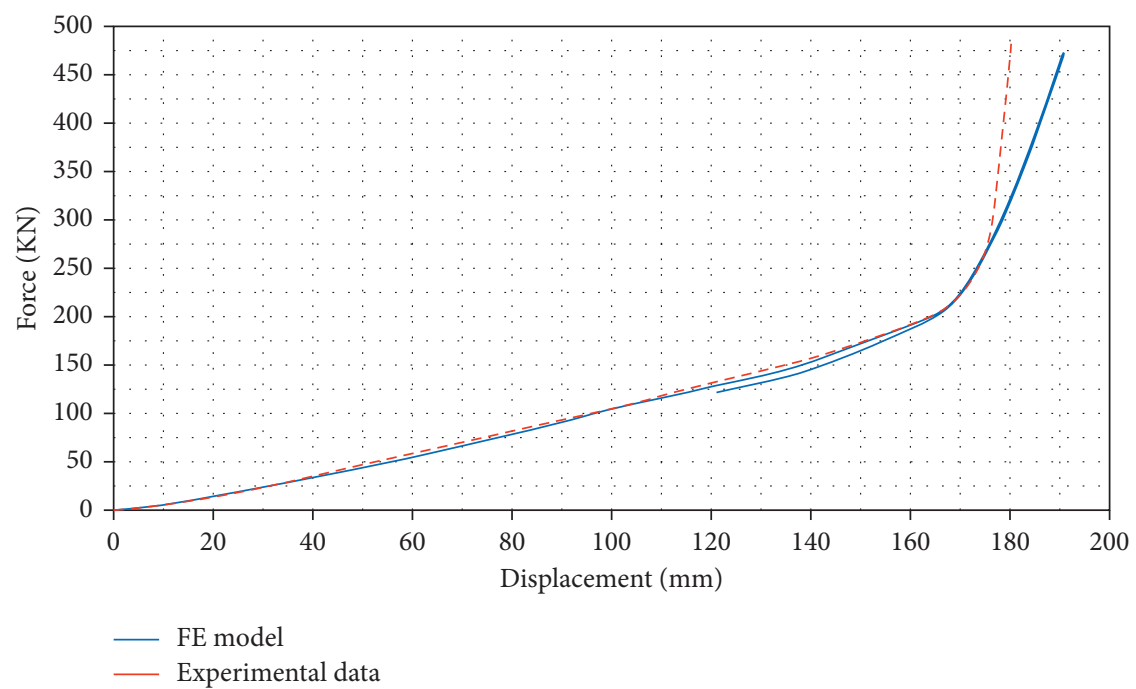

Figure 26: Numerical and experimental vertical forces vs. tyre displacement. 


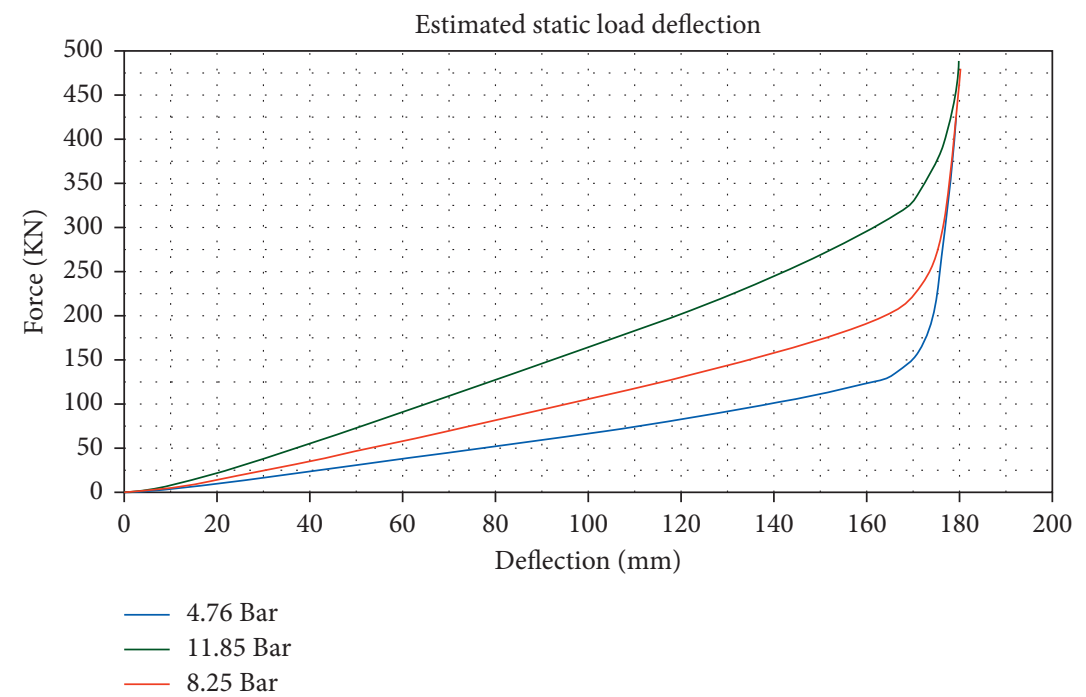

FIgURE 27: Numerical vertical forces vs. tyre displacement curves as a function of the tyre pressure.

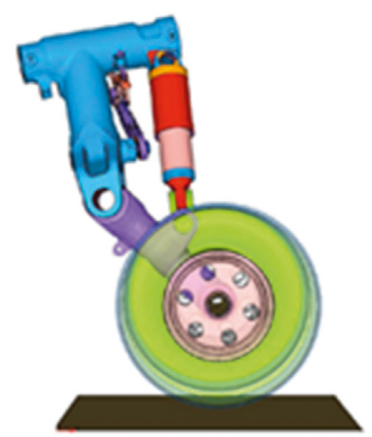

(a)

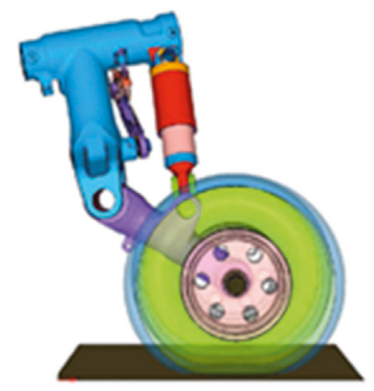

(c)

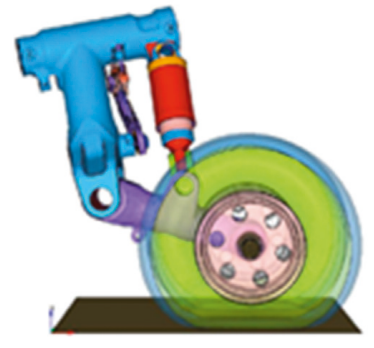

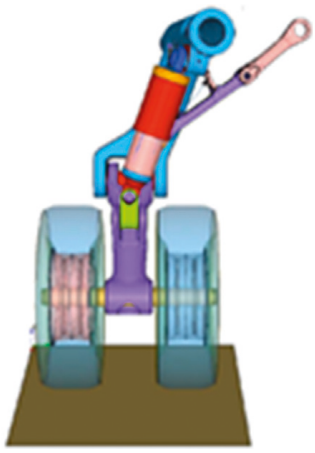
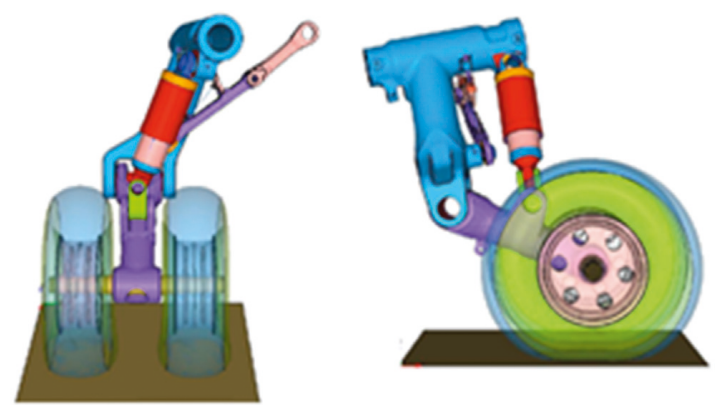

(d)
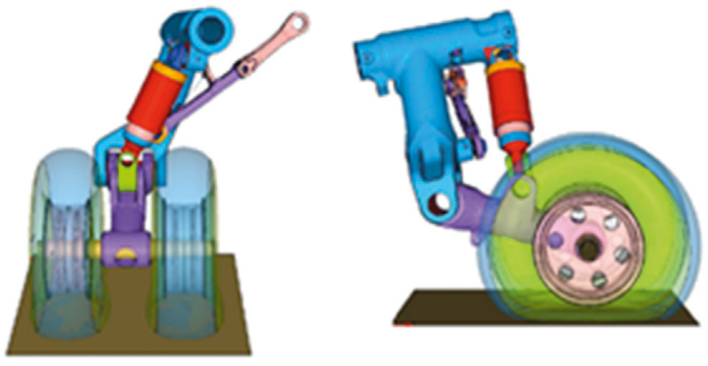

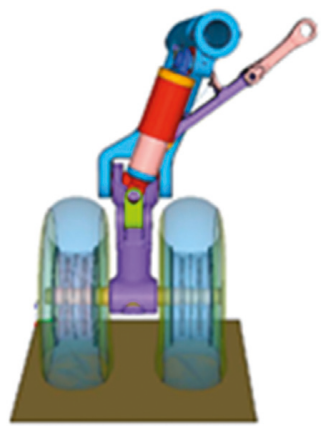

(b)
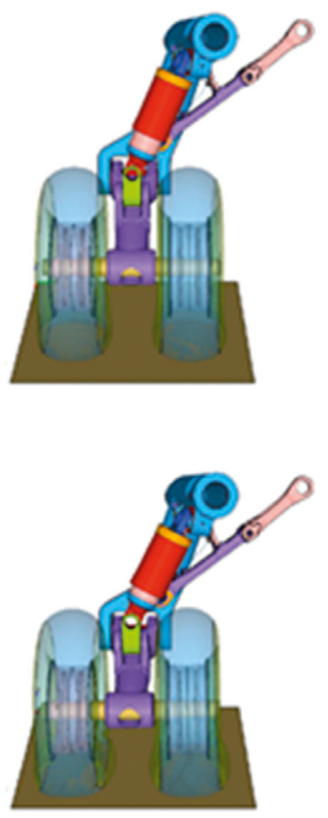

(e)

(f)

FIGURE 28: Continued. 


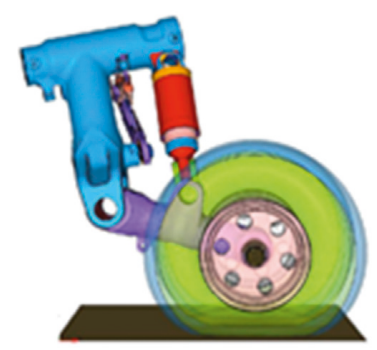

(g)

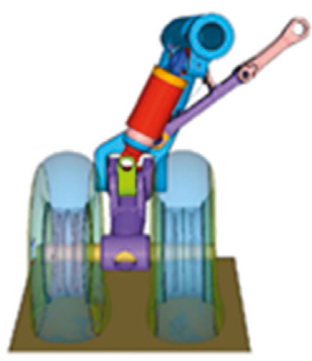

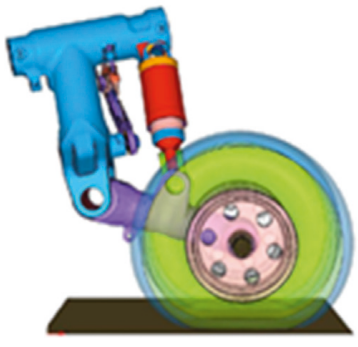

(h)

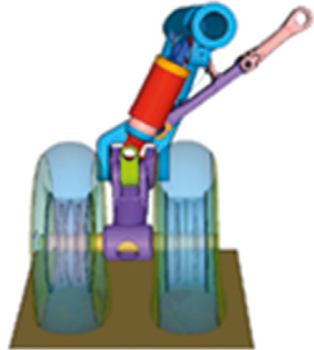

Figure 28: Numerical frames of the drop test simulation: (a) $t 1=0 \mathrm{~ms}$; (b) $t 2=50 \mathrm{~ms}$; (c) $t 3=80 \mathrm{~ms}$; (d) $t 4=120 \mathrm{~ms}$; (e) $t 5=170 \mathrm{~ms}$; (f) $t 6=210 \mathrm{~ms} ;(\mathrm{g}) t 7=340 \mathrm{~ms} ;$ (h) $t 8=350 \mathrm{~ms}$.

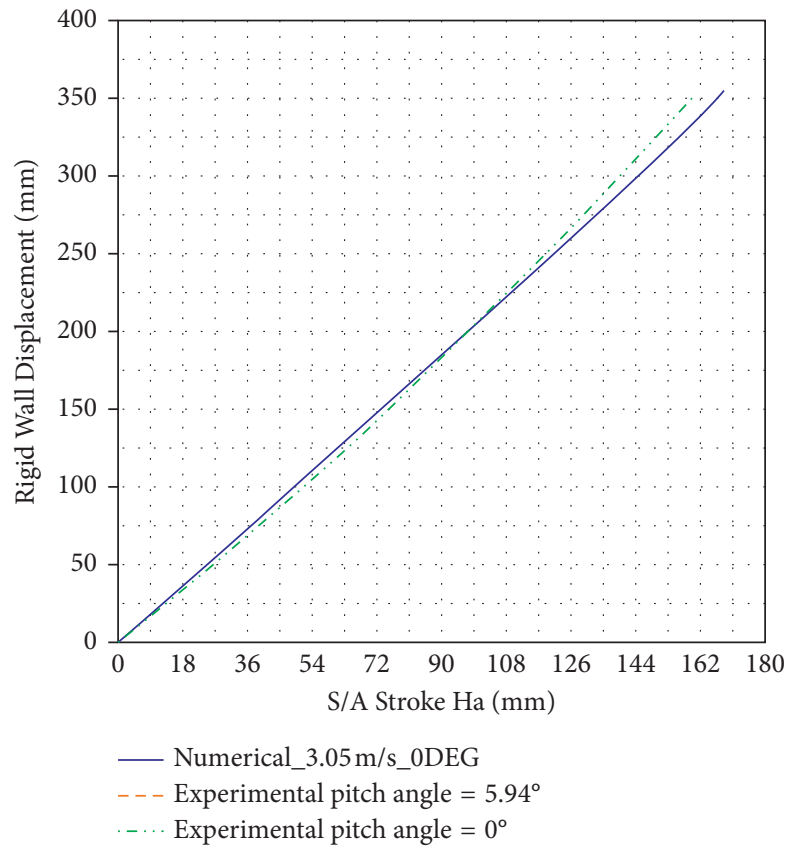

(a)

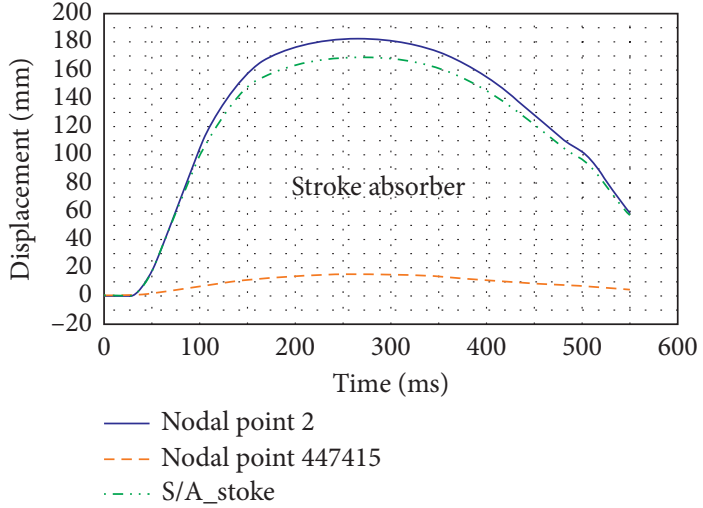

(b)

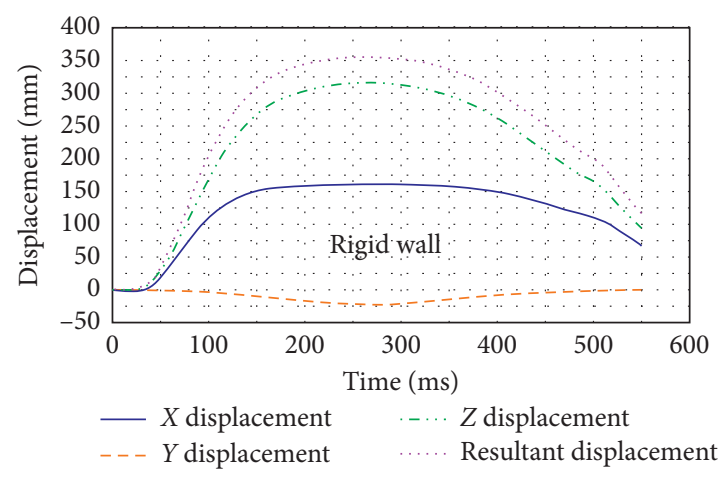

(c)

FIGURE 29: (a) Shock absorber stroke vs. rigid wall displacement curves; (b) shock absorber stroke vs. time curves; (c) rigid wall displacement vs. time curves. 


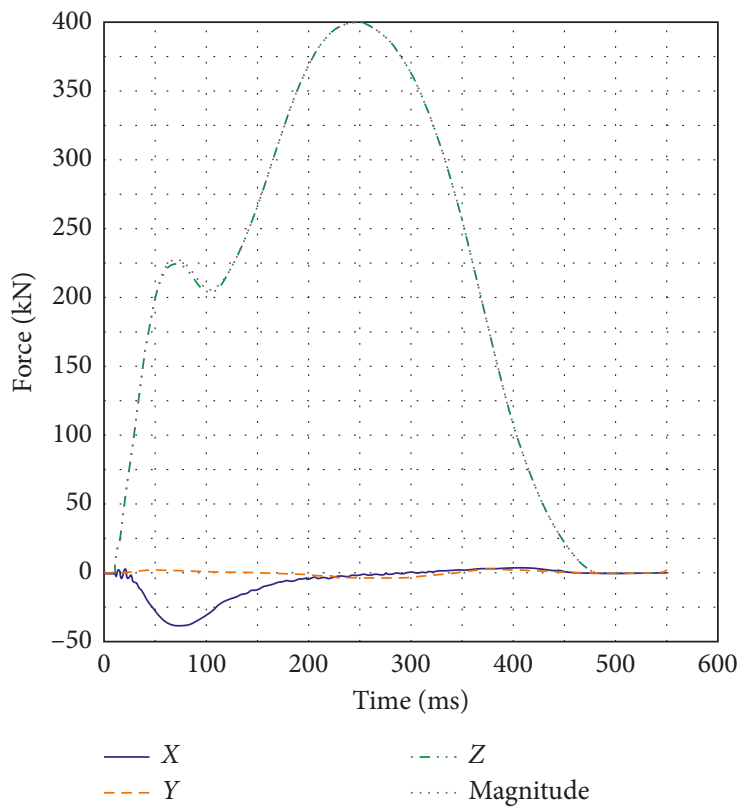

Figure 30: Contact force between tyre and rigid wall.

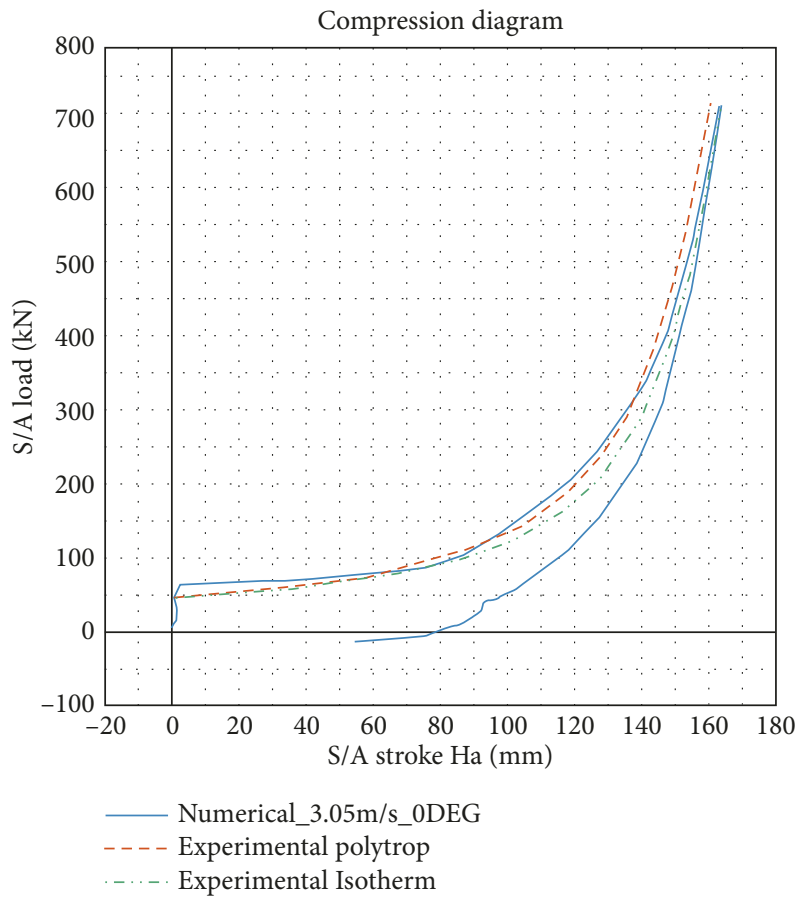

(a)

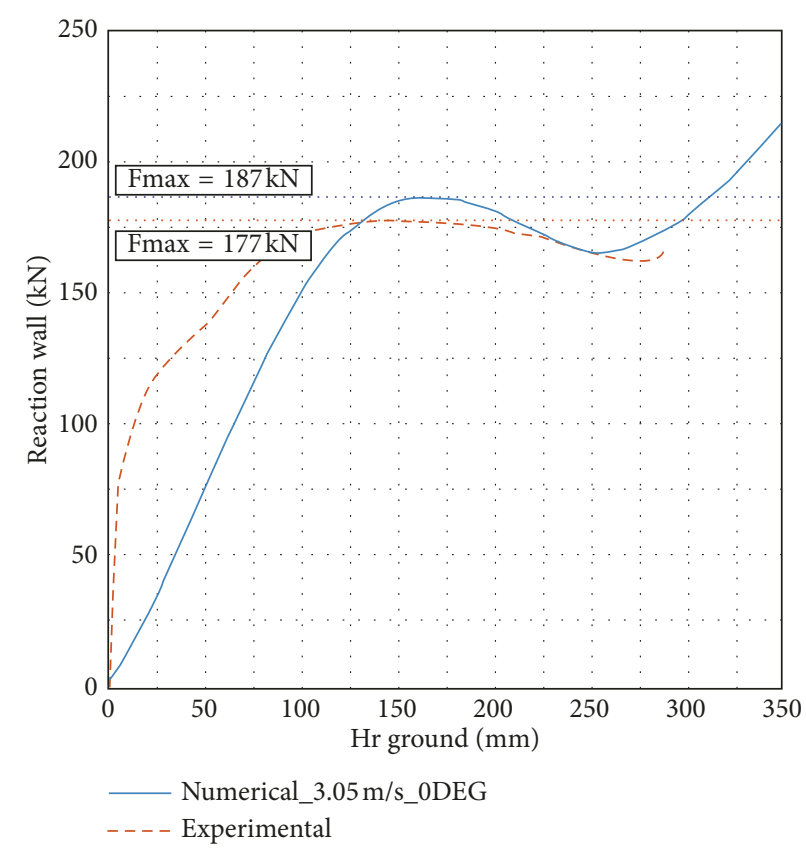

(b)

FIGURE 31: Shock absorber reaction vs. stroke curves.

Figure 31(a) shows the numerical and experimental shock absorber (S/A) reactions plotted as a function of the stroke. Finally, Figure 31(b) shows the numerical contact force compared with the respective experimental one, between the wall and one of the two tyres, as a function of the relative displacement between wheel and rigid wall.

According to Figure 31, a good agreement has been achieved in terms of peak between numerical and experimental results.
The reaction forces have also been monitored during the dynamic simulation (Figure 32) and compared to the stick model ones (Table 4), presented in Section 4, representative of the static configuration equivalent to the tail down landing configuration.

According to Figure 32, nodes 52, 55, and 56 correspond to the constrains locations modelled in the Ls-Dyna model (Figure 33), which coordinates are the same of nodes 52, 55, and 56 of the stick model in Figure 3. 


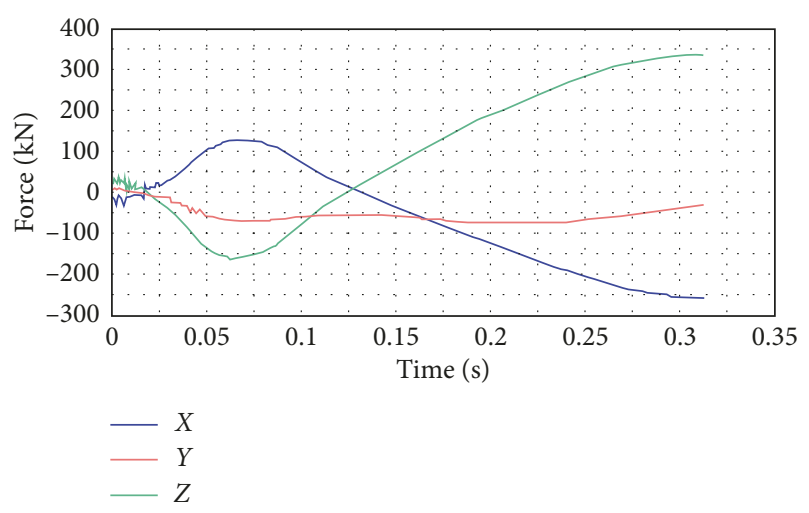

(a)

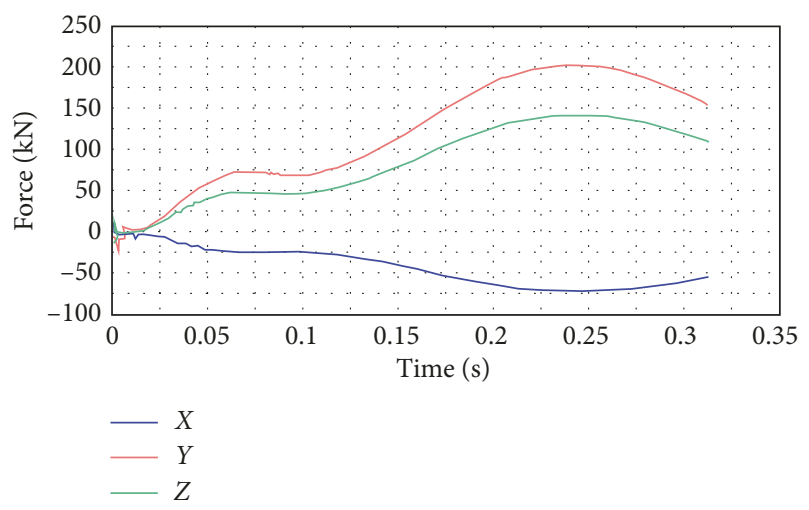

(c)

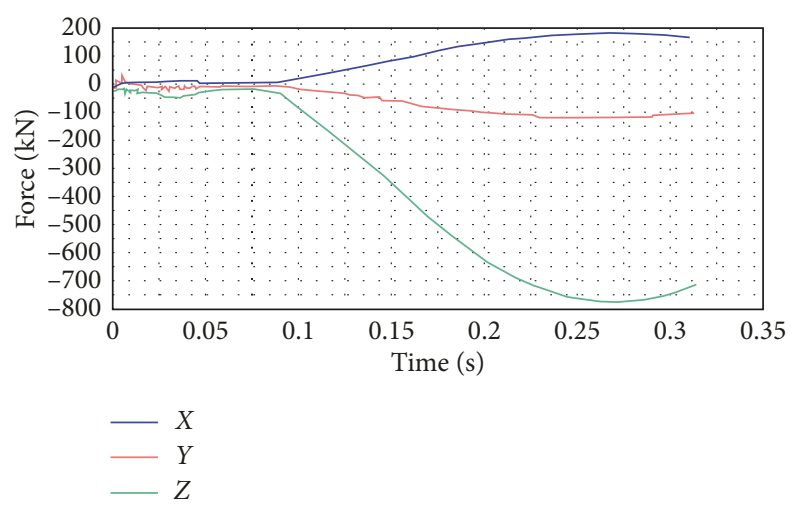

(b)

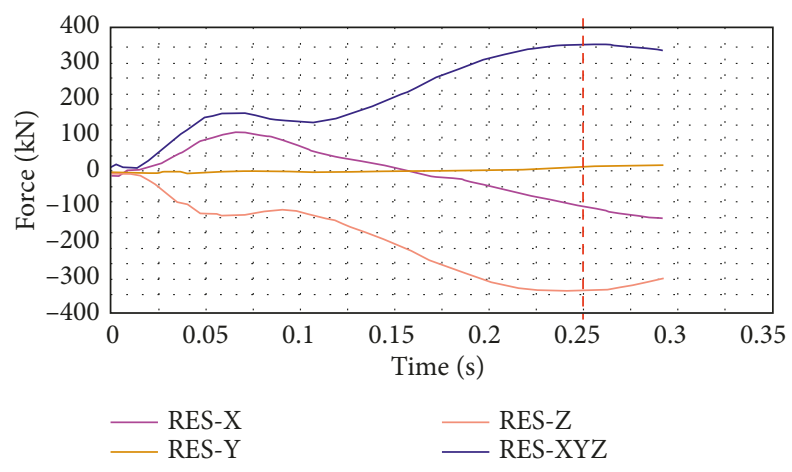

(d)

Figure 32: Reaction forces of full-FE model. (a) Node 52. (b) Node 55. (c) Node 66. (d) Resultant Forces.

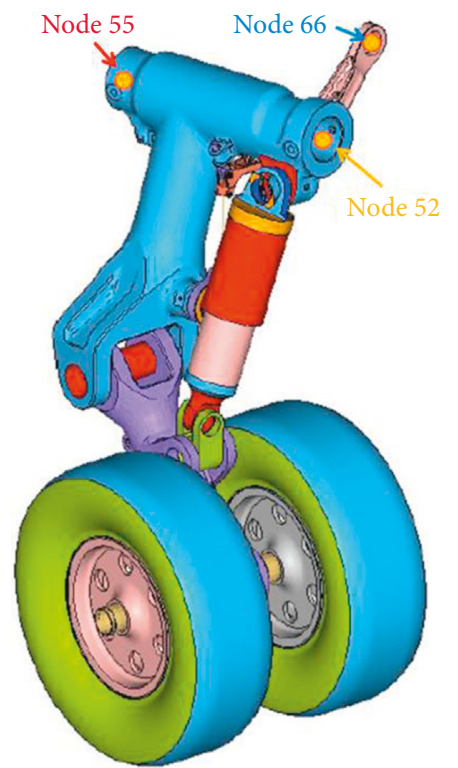

FIgURE 33: 3D full-FE constraints locations.

The comparison between the reaction forces achieved by both numerical models is shown in Table 6.

According to Table 6, the single contributes and the resultant of the reaction forces carried out by the two modelling techniques are significantly far from each other.
TABLE 6: Reaction forces achieved by the stick and 3D full-FE models during the drop test.

\begin{tabular}{lccc}
\hline Models & $\mathrm{Rx}(\mathrm{N})$ & $\mathrm{Ry}(\mathrm{N})$ & $\mathrm{Rz}(\mathrm{N})$ \\
\hline Node 52 & & & \\
Stick model & -14420 & -97770 & -35078 \\
Ls-Dyna model & -201000 & -68900 & 283800 \\
\hline Node 55 & & & \\
Stick model & 102047 & -154301 & -350578 \\
Ls-Dyna model & 177700 & -123800 & -764000 \\
\hline Node 66 & & & \\
Stick model & -87626 & 252071 & 177144 \\
Ls-Dyna model & -70800 & 200700 & 141800 \\
\hline
\end{tabular}

This comparison has been performed by considering the maximum value of the full-FE forces resultant, carried out at $0.25 \mathrm{~s}$ of the time analysis (Figure 32 ). The disagreement is due to the simplification of the stick model. The stress analysis has also been carried out at this instant of time. Figure 34 shows the von Mises stress contour plot of the main fitting.

The maximum value of the von Mises stresses can be noticed in correspondence of the pin linking the main fitting to the shock absorber, by reaching a value of $470 \mathrm{MPa}$, which is higher than the yield stress.

Hence, plastic deformation affects the main fitting of the landing gear just around the hole, as shown in Figure 35. 


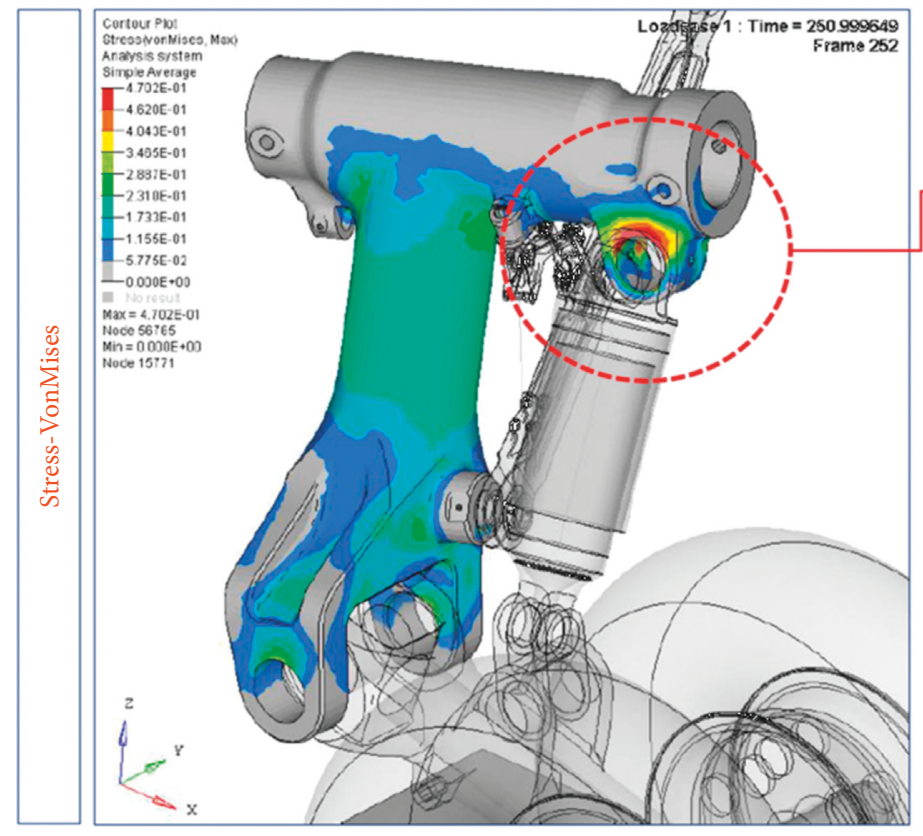

Max stress@ (250 ms)

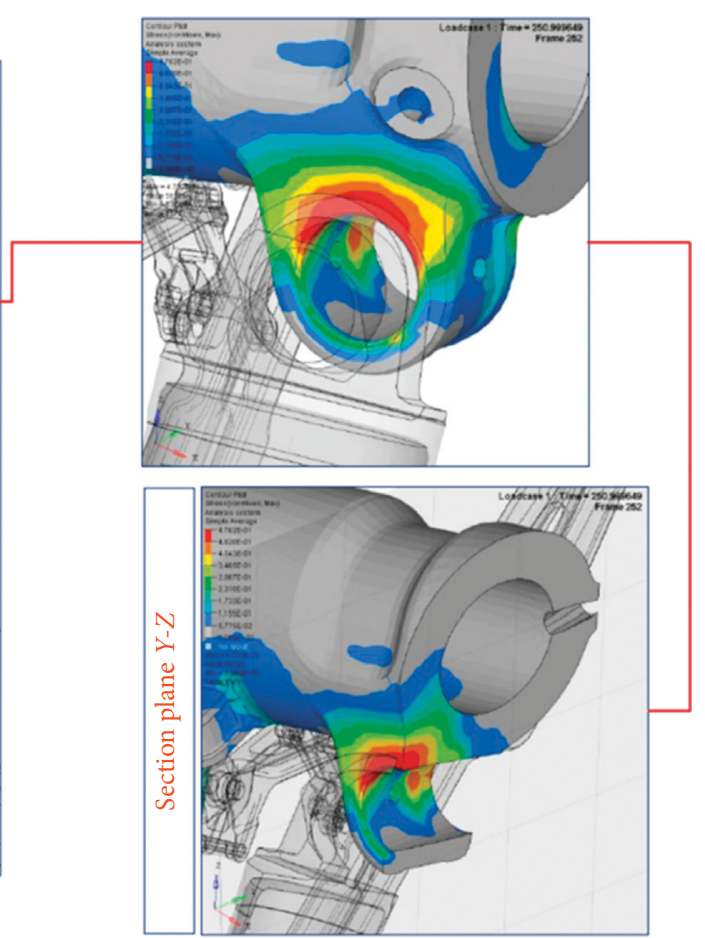

Figure 34: von Mises stress (GPa) contour plot for the main fitting.
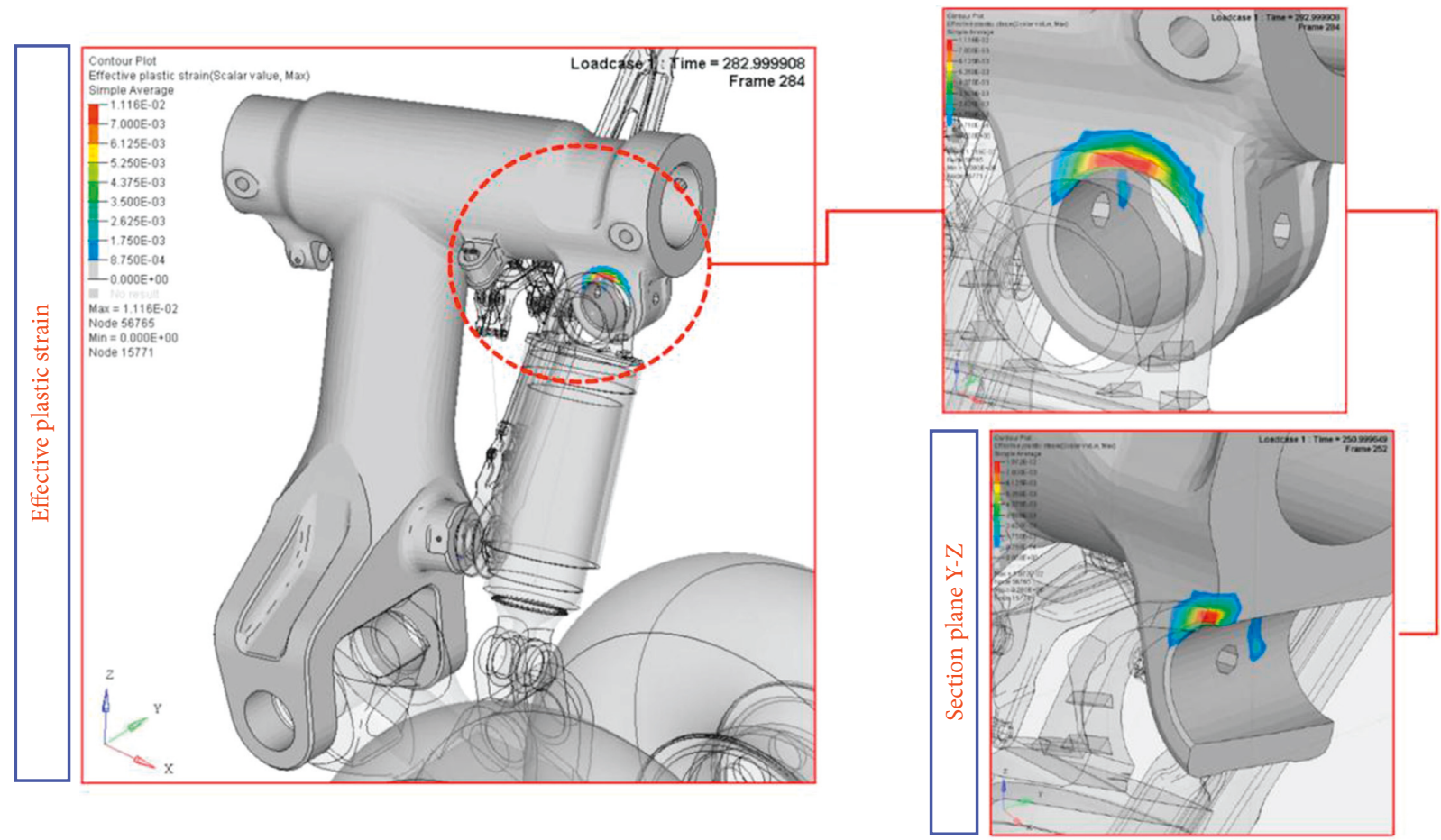

Figure 35: Effective plastic strain map for the main fitting.

Figure 36 shows the von Mises stress contour plot concerning the other structural components and, in particular, the trailing arm.
As well as the main fitting, also the trailing arm, as a result of the drop test, is affected by some plastic deformations as shown in Figure 37. 

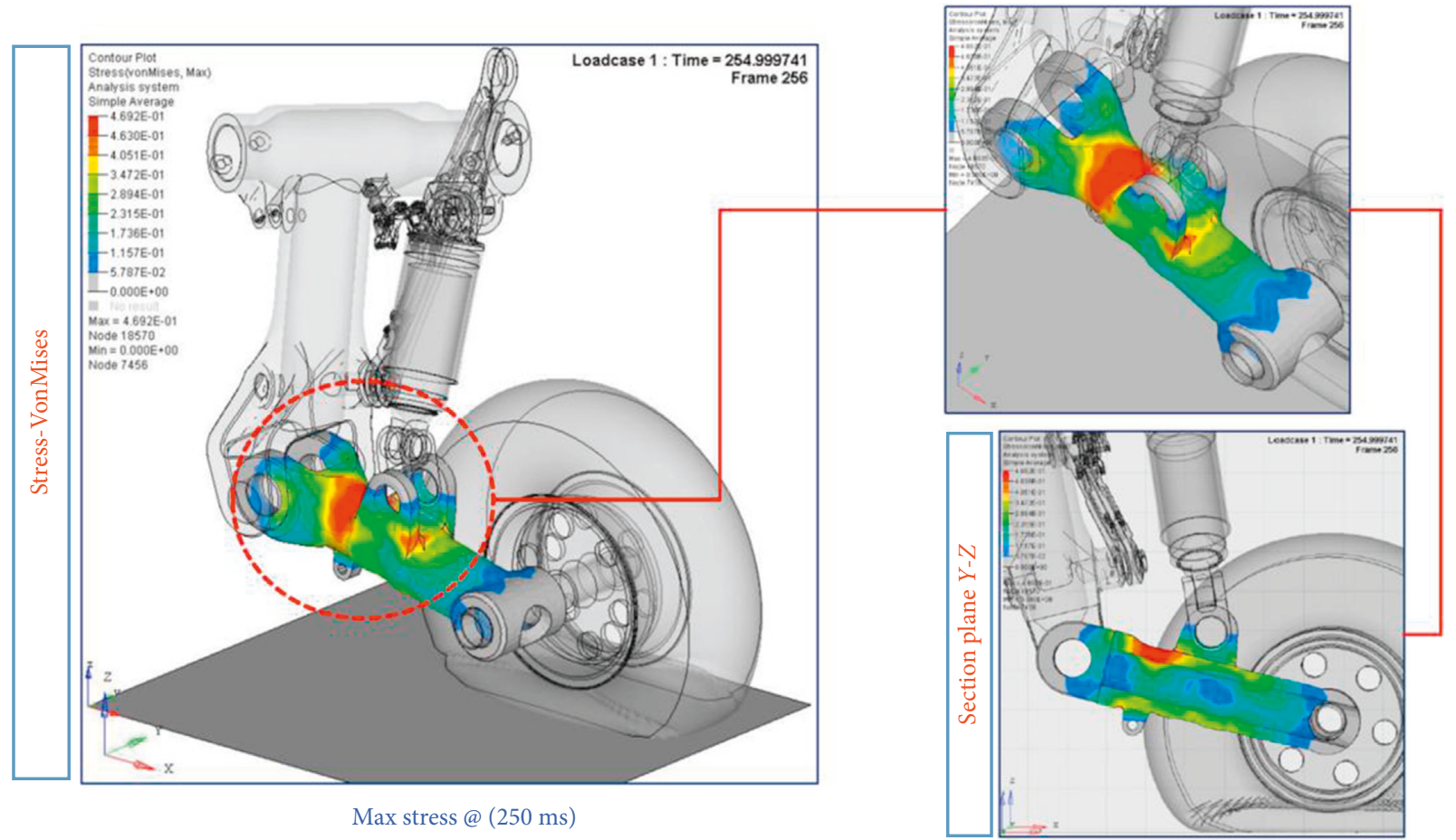

Figure 36: von Mises stress (GPa) contour plot for the trailing arm.

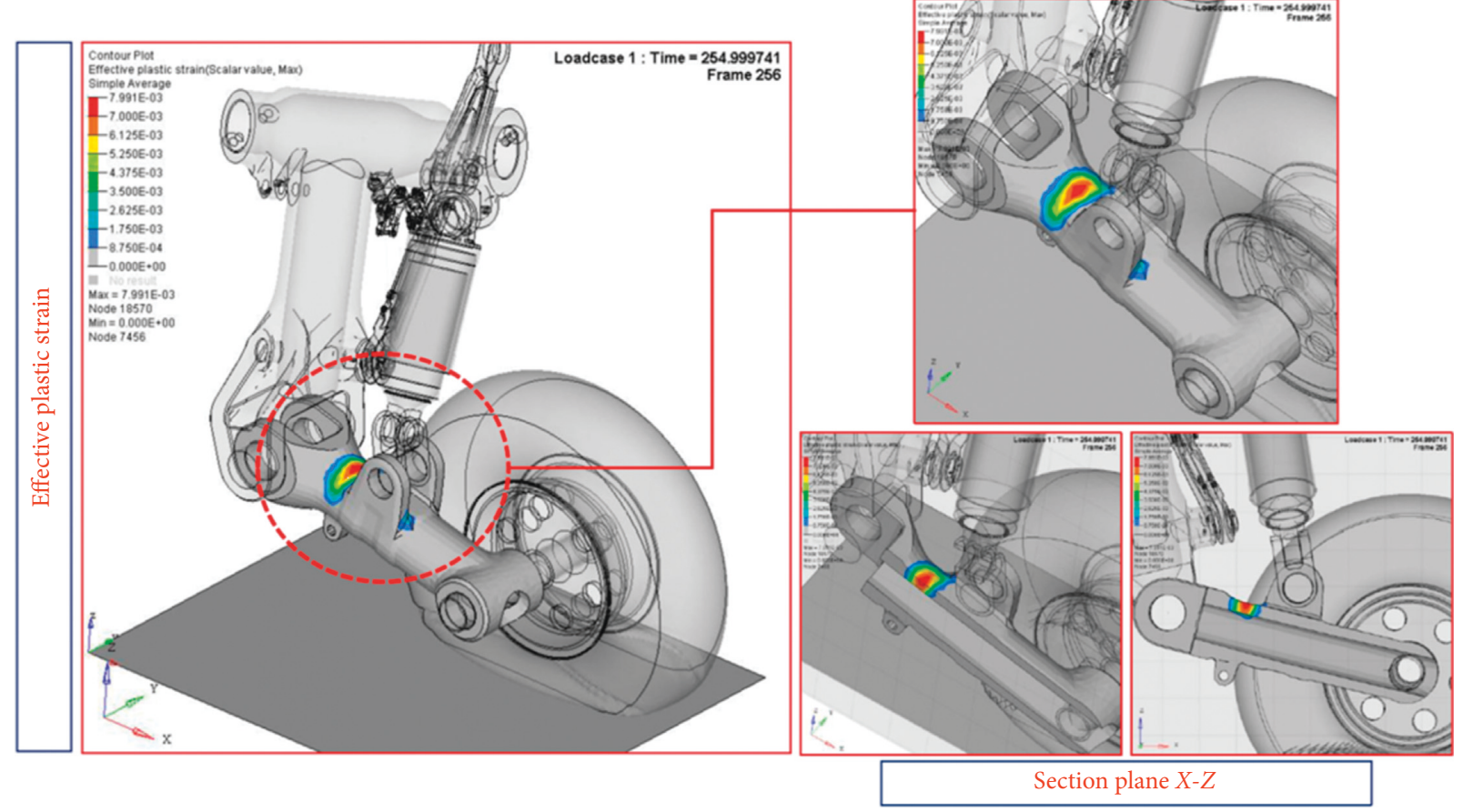

FIGURE 37: Effective plastic strain map for the trailing arm.

\section{Conclusions}

Three numerical models, based on MB, stick, and 3D full-FE methods, have been developed in order to investigate the reaction forces acting on a landing gear of a regional airliner under static loading conditions. The former has been developed in ADAMS $^{\circledR}$, the two latter in NASTRAN ${ }^{\circledR}$. Numerical results have been compared with each other in order to understand their effectiveness; a very good level of agreement has been achieved. 
Subsequently, a Global/Local technique has been presented; specifically, starting from the stick model, each component, modelled with one-dimensional finite elements, is replaced, once at time, with a three-dimensional finite element representation. Then structural analyses have been, then, carried out and the stresses fields on the 3D components have been investigated and compared with the stresses field obtained by a 3D full-FE model. Also in these cases, a good agreement has been achieved.

Finally, the dynamic behaviour of the landing gear has been investigated both numerically and experimentally. Magnaghi Aeronautica S.p.A. Company performed the experimental test, consisting of a drop test performed with reference to EASA CS 25 regulations. Concerning the numerical investigation, the analysis has been simulated by means of Ls-Dyna ${ }^{\circledR}$ code, by developing a 3D full-FE model; a good level of accuracy has been achieved.

It must be highlighted that an established numerical model can be used for Certification by Analysis (CBA) purposes to test new structural solutions in a virtual environment, by reducing the high experimental costs and by overcoming the issues which characterize the design current practice of landing gear. Nowadays, in fact, the compliance assessment of new landing gear concepts with the requirements is postponed until later design stage by performing experimental tests on prototypes, involving expensive design modifications in the case that the landing gear design fails to meet the customer and certification requirements.

\section{Data Availability}

The data used to support the findings of this study were supplied by Magnaghi S.p.A. under license and so cannot be made freely available. Requests for access to these data should be made to corresponding authors e-mail: raffsepe@ unina.it.

\section{Conflicts of Interest}

The authors declare that they have no conflicts of interest.

\section{Acknowledgments}

The research activity has been developed within CAPRI "Landing gear with intelligent implementation" Research Project founded by Regione Campania, Italy.

\section{References}

[1] M. Imran, R. M. Shabbir Ahmed, and M. Haneefc, "FE analysis for landing gear of test air craft," Materials Today: Proceedings, vol. 2, no. 4-5, pp. 2170-2178, 2015.

[2] L. Hailiang and W. Lixin, "Assessment of landing gear design based on the virtual testing and evaluation methodology," Procedia Engineering, vol. 99, pp. 898-904, 2015.
[3] A. G. Barnes and T. J. Yager, Enhancement of Aircraft Ground Handling Simulation Capability, AGARD-AG-333, AGARD, Neuilly sur Seine, France, 1998.

[4] G. R. Doyle Jr., "A review of computer simulations for aircraft-surface dynamics," Journal of Aircraft, vol. 23, no. 4, pp. 257-265, 1986.

[5] D. Williams and R. P. N. Jones, Dynamic Loads in Aeroplanes under Given Impulsive Loads with Particular Reference to Landing and Gust Loads on a Large Flying Boat, TR No. 2221, Aeronautical Research Council, UK, 1948.

[6] A. E. McPherson, J. Evans Jr., and S. Levy, Influence of Wing Flexibility on Force-Time Relation in Shock Strut following Vertical Landing Impact, NACA TN 1995, NACA, Washington, DC, USA, 1949.

[7] F. E. Cook and B. Milwitzky, Effect of Interaction on LandingGear Behavior and Dynamic Loads in a Flexible Airplane Structure, United States, NACA TR 1278, NACA, Washington, DC, USA, 1956.

[8] W. G. Luber, E. Dill, and K. Kainz, "Dynamic landing loads on combat aircraft with external stores using finite element models," in Proceedings of Conference and Exposition on Structural Dynamics (IMAC-XXV), pp. 19-22, Orlando, FL, USA, February 2007.

[9] J. L. Pérez, L. H. Benítez, M. Oliver, and H. Climent, "Survey of aircraft structural dynamics nonlinear problems and some recent solutions," Aeronautical Journal, vol. 115, no. 1173, pp. 653-668, 2011.

[10] P. Suresh, S. Nesar, and G. Radhakrishnan, "Dynamic landing response analysis of a flexible tailless delta wing aircraft," International Journal of Aerospace Innovations, vol. 4, no. 3-4, pp. 103-117, 2012.

[11] D. H. Chester, "Aircraft landing impact parametric study with emphasis on nose gear landing conditions," Journal of Aircraft, vol. 39, no. 3, pp. 394-403, 2002.

[12] T. L. Lomax, Structural Loads Analysis for Commercial Aircraft: Theory and Practice, AIAA Education Series, AIAA, Reston, VA, USA, 1996, ISBN-13: 978-1563471148.

[13] F. Caputo, A. De Luca, A. Greco, S. Maietta, A. Marro, and A. Apicella, "Investigation on the static and dynamic structural behaviours of a regional aircraft main landing gear by a new numerical methodology," Frattura ed Integrita Strutturale, vol. 12, no. 43, pp. 191-204, 2018.

[14] J. N. Daniels, A Method for Landing Gear Modeling and Simulation With Experimental Validation, NASA Contractor Report 201601, National Aeronautics and Space Administration, Washington, DC, USA, 1996.

[15] T. Niezgoda, J. Malachowski, and W. Kowalski, "Numerical simulation of landing gear dynamics," in Mecanica Computacional, S. R. Idelsohn, V. E. Sonzongni, and A cardona, Eds., vol. XXI, pp. 2579-2586, Asociación Argentina de Mecánica Computacional, Santa Fe, Parana, Argentina, October 2002.

[16] V. Infante, L. Fernandes, M. Freitas, and R. Baptista, "Failure analysis of a nose landing gear fork," Engineering Failure Analysis, vol. 82, pp. 554-565, 2017.

[17] S. Redonnet, S. Ben Khelil, J. Bulté, and G. Cunha, "Numerical characterization of landing gear aeroacoustics using advanced simulation and analysis techniques," Journal of Sound and Vibration, vol. 403, pp. 214-233, 2017.

[18] W. T. Fujimoto and J. P. Gallagher, Summary of Landing Gear Initial Flaws, AFFDL-TR-77-125, DTIC, Fort Belvoir, VA, USA, 1977.

[19] D. Viúdez-Moreiras, M. Martín, R. Abarca, E. Andrés, J. Ponsín, and F. Monge, "Surrogate modeling for the main landing gear doors of an airbus passenger aircraft," 
Aerospace Science and Technology, vol. 68, pp. 135-148, 2017.

[20] European Aviation Safety Agency, Certification Specifications and Acceptable Means of Compliance for Large Aeroplanes CS25 EASA, European Aviation Safety Agency, Cologne, Germany, 2016.

[21] Federal Aviation Administration, Federal Aviation Regulations Part 25-Airworthiness standards: transport category airplanes (FAR25), Washington, DC, USA, 2018.

[22] MSC, Nastran User Reference Manual, MSC Software Corporation, Santa Ana, CA, USA, 2006.

[23] MSC, ADAMS User Reference Manual 2015, MSC Software Corporation, Santa Ana, CA, USA, 2015.

[24] J. O. Hallquist, Ls-Dyna Theory Manual, ISBN 0-9778540-0-0, LSTC, Livermore, CA, USA, 2006. 


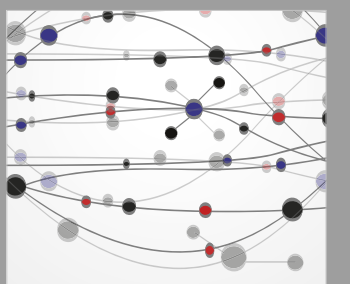

The Scientific World Journal
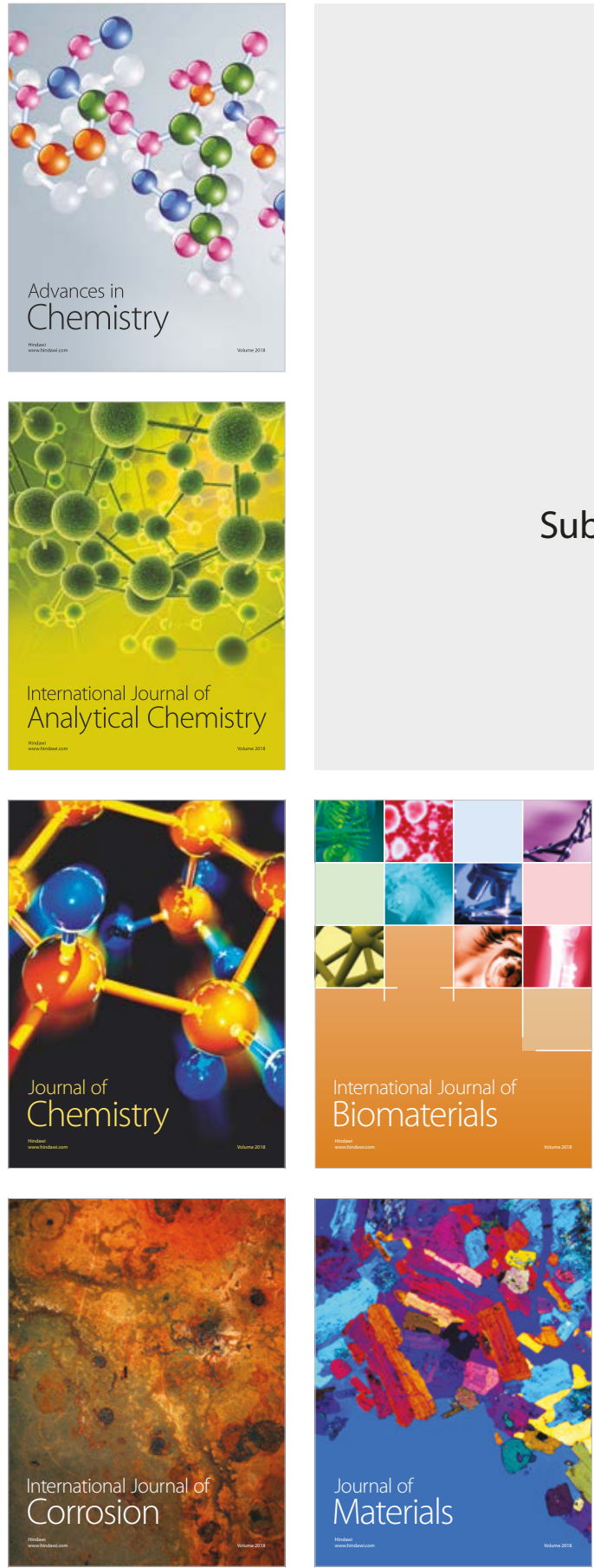

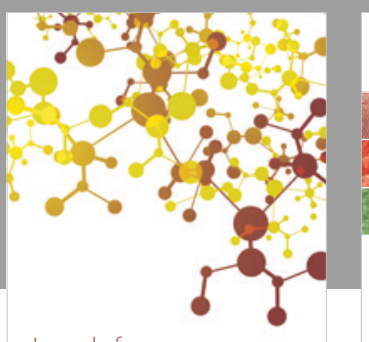

Journal of

Applied Chemistry
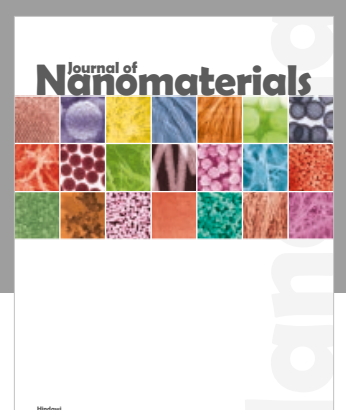

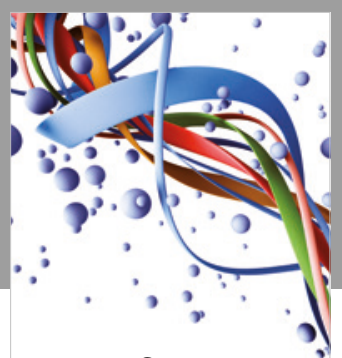

Scientifica

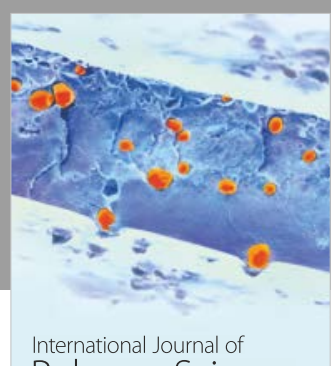

Polymer Science

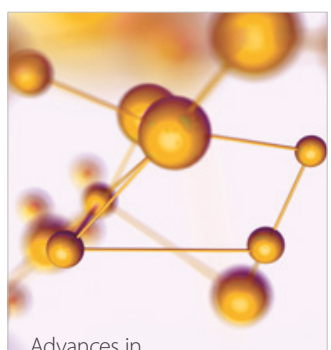

Physical Chemistry
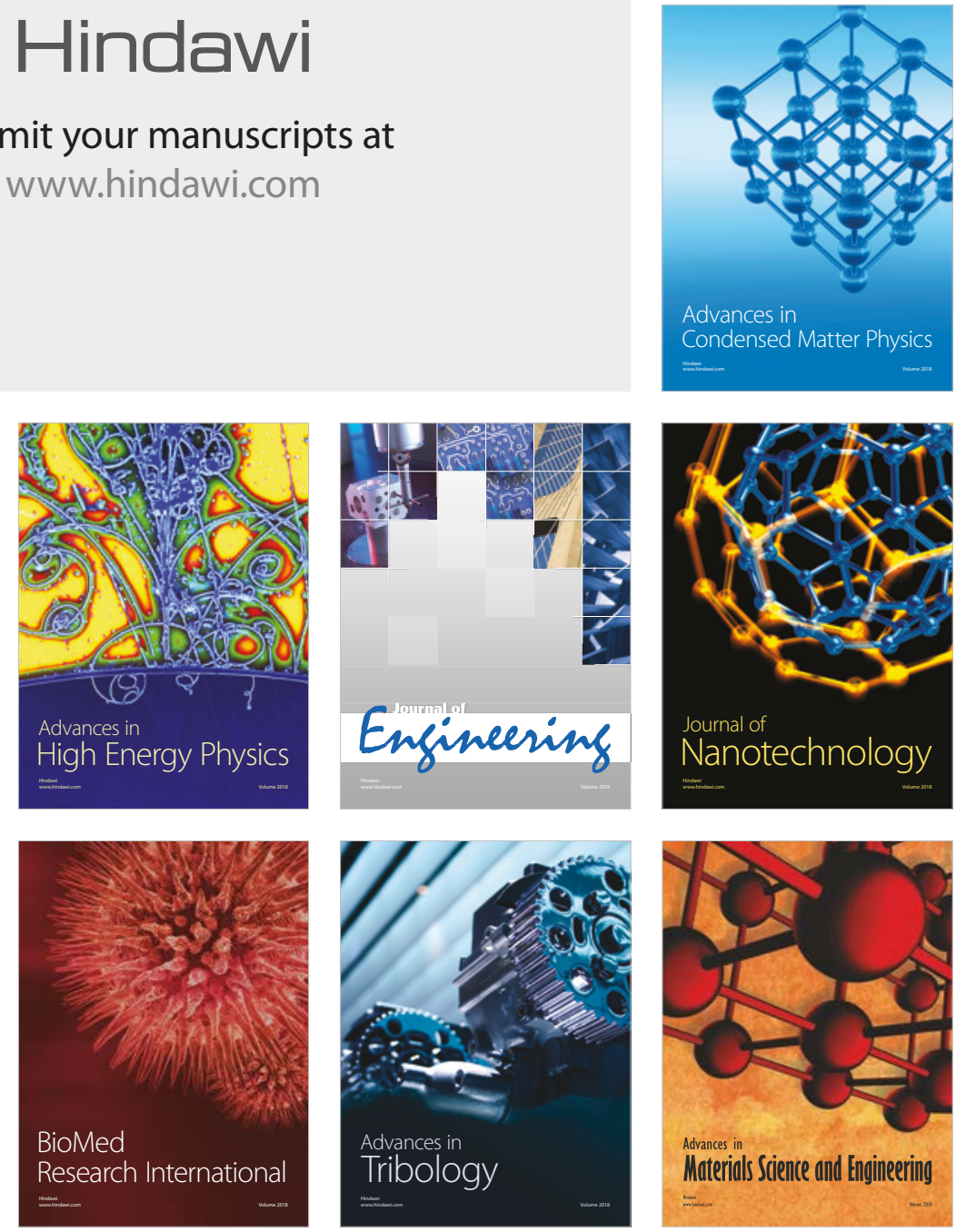